\section{Arrkivoc

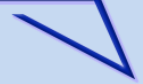 \\ A Platinum Open Access Journal \\ for Organic Chemistry}

Free to Authors and Readers
DOAJ Seal
Review

Arkivoc 2021, part vi, 174-221

\title{
ED-ROP of macrocyclic oligomers: A synthetic tool for multicomponent polymer materials
}

\author{
Paola Stagnaro, * Elisabetta Brunengo, and Lucia Conzatti \\ Istituto di Scienze e Tecnologie Chimiche "Giulio Natta" - National Research Council of Italy \\ SCITEC-CNR, Via De Marini 6, 16149 Genova (Italy) \\ Email: paola.stagnaro@scitec.cnr.it
}

Dedicated to Emeritus Professor Philip Hodge for his outstanding contribution to the studies on strainless macrocyclic oligomers and their entropically-driven ring-opening polymerization

Received 07-20-2021

Accepted 09-07-2021

Published on line 09-24-2021

\section{Abstract}

Entropically-driven ring-opening polymerization (ED-ROP) of strainless macrocyclic oligomers (MCOs) of condensation polymers has received a great deal of attention in the past three decades. Typical features of EDROP, such as no need for solvents, no emission of volatiles, practically no heat evolution, no particular need for mixing, automatic stoichiometric balance, make this process a useful synthetic tool in a variety of applications involving polymers of industrial interest. Selected examples exploiting ED-ROP of MCOs to (i) achieve multicomponent polymer materials (copolymers, blends, composites and nanocomposites), (ii) aid melt processing, (iii) enhance phase compatibility, (iv) modify material properties or (v) allow chemical recycling are reviewed.

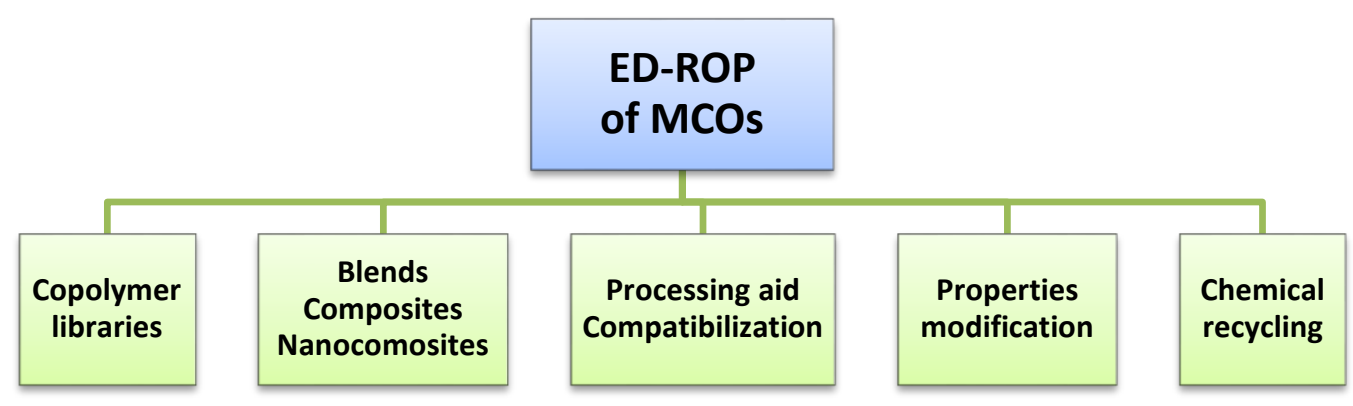

Keywords: Entropically-driven ring-opening polymerization (ED-ROP), macrocyclic oligomers (MCOs), copolymers, (nano)composites, processing, recycling 


\section{Table of Contents}

1. Introduction

2. Copolymer Synthesis through ED-ROP

2.1. Copolyesters

2.2. Other copolymers

3. ED-ROP for Polymer Blends, Composites and Nanocomposites

3.1. Blends

3.2. Composites

3.2.1. Traditional fiber-reinforced composites

3.2.2. Eco-composites with natural fibers

3.2.3. Composites with micrometric particulate fillers

3.3. Nanocomposites

3.3.1. 3D nanoparticles

3.3.2. 2D nanoparticles

3.3.3. $1 \mathrm{D}$ nanoparticles

3.3.4. OD nanoparticles

4. Other Applications of ED-ROP

4.1. Processing aid

4.2. Compatibilization

4.3. Properties modification

4.4. Materials recycling

5. Conclusions

Acknowledgements

References

Authors' biographies

\section{Introduction}

Since its appearance in the literature, entropically-driven ring-opening polymerization (ED-ROP) of strainless macrocyclic oligomers (MCOs) has been shown to be not only an issue of theoretical curiosity, ${ }^{1-4}$ but also of practical importance as an alternative approach to synthesis and processing of condensation polymers, 5,6 amongst which many are of relevant industrial interest, such as polyesters, polycarbonates, some polyamides, poly(ether ketone)s and poly(ether sulfone)s.

ED-ROP reactions exploit the well-known ring-chain equilibria (RCE) characterizing polycondensate systems. In virtue of such RCE, in the presence of a suitable catalyst to facilitate formation and rupture (reshuffling) of the linkages between the repeat units, the linear polymer can interconvert into its homologous family of cyclic oligomers. The RCE position strictly depends on the system concentration: at low concentrations (typically below 3\% wt/vol) the formation of MCOs is greatly favored whereas at high concentrations (better in neat conditions) the linear polymer is predominant (Scheme 1). Neat equilibrated systems, e.g., commercial polycondensates, typically contains ca. $98 \%$ and ca. $2 \%$ by weight of linear polymer chains and MCOs, respectively. 7,8 
It is worth noting that in a recent work Kricheldorf and co-workers ${ }^{9}$ found some flaws in the original Jacobson-Stockmayer theory, ${ }^{1,2}$ in particular with regard to critical concentration. Nevertheless, this has no substantial implications on the practical applications of ED-ROP that will be reviewed in the following.

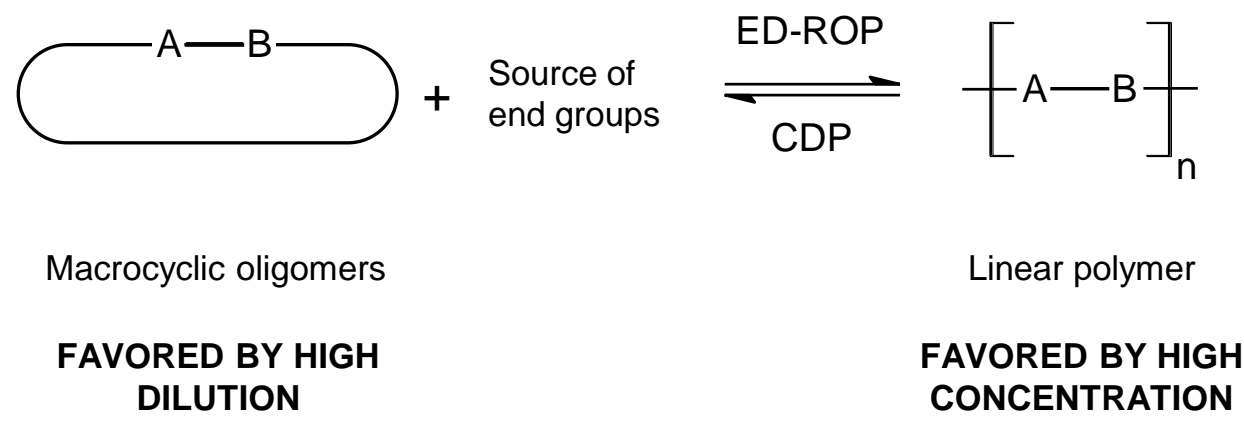

Scheme 1. Ring-chain equilibria based on ED-ROP and CDP reactions.

Macrocyclic oligomers (MCOs) are defined as strainless when they contain at least 14 skeletal atoms in their rings; in such a case, enthalpy variation upon ring opening polymerization is negligible and the process is actually driven by the conformational gain in entropy the linear macromolecules being formed have over their cyclic counteparts. ${ }^{10,11}$

Aside from the pioneering works of Carothers and collaborators, ${ }^{12,13}$ who synthesized aliphatic cyclic oligomeric esters and carbonates by distillative depolymerization of the linear parent polymers, most of the subsequent studies on MCOs up to the 1990s were of academic interest.

Methods to prepare $\mathrm{MCOs}^{14}$ can be grouped in the main categories briefly listed in the following. The first comprises high-dilution syntheses, ${ }^{15}$ where the concentration of the linear species bearing the reactive end groups is sufficiently low to favor intramolecular reactions over intermolecular ones. However, high dilutions require large volumes of solvent, which poses environmental issues. When the macrocycles, once formed, are sufficiently stable under the reaction conditions, pseudo-high dilution methods can be called upon. ${ }^{16,17}$ In this case the reactants are added to the reaction mixture slowly so that a low concentration of reactants is maintained throughout the course of the reaction. In such a way the cyclic products can accumulate in the reaction medium so much so that multi-kilogram quantities can be easily achieved. ${ }^{18} \mathrm{~A}$ third methodology developed to prepare MCOs is the so-called polymer-supported cyclo-oligomerization. ${ }^{19,20}$ Such a method is suitable when the repeat units are of the A-B type (e.g., hydroxy acids). As sketched in Scheme 2, the starting species are attached to the polymeric support (typically chloromethylated cross-linked polystyrene beads) through one type of end group, a supported cyclization reaction then forms the oligomeric cycles, which having no more end groups are released in solution and can be easily separated from the linear species, the latter remaining attached to the support. 


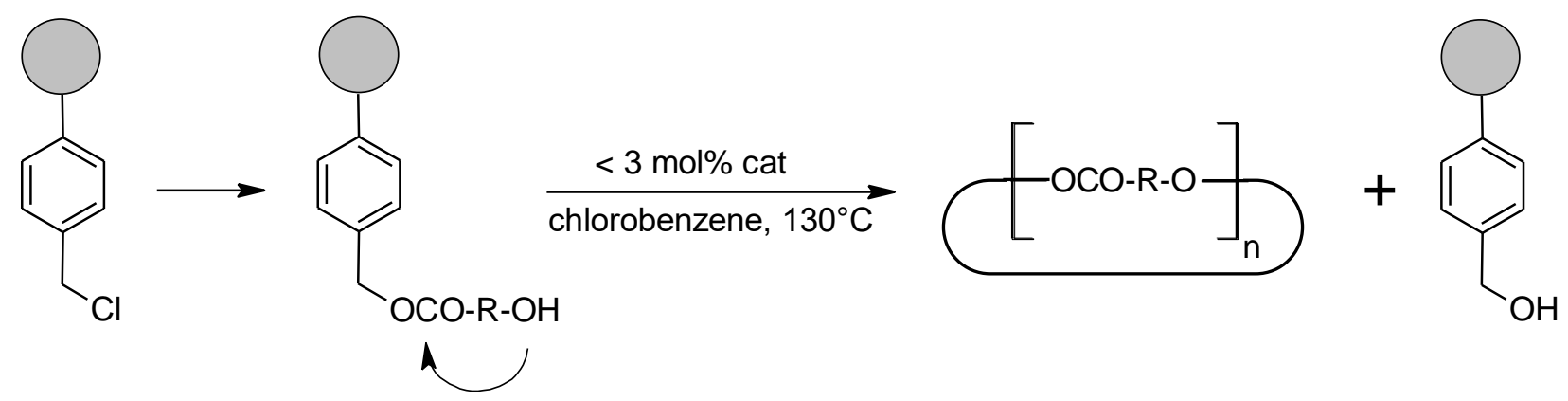

Scheme 2. A generalized example of polymer-supported cyclo-oligomerization.

Another interesting method to achieve MCOs is cyclo-depolymerization (CDP), which is exactly the reverse of ED-ROP (see Scheme 1). ${ }^{21,22}$ In conditions of hot dilute solution (typically < 3\% wt/vol) and in the presence of a proper catalyst, a linear condensation polymer can depolymerize to establish the RCE, which lies in favor of MCOs. Thus, homologous families of MCOs with increasing ring sizes can be achieved from the parent linear polymers via a simple one-step CDP process in batches of about $25 \mathrm{~g} .{ }^{14} \mathrm{~A}$ less diffuse technique to prepare MCOs is enzymatic cyclization/depolymerization (EC/ED), where macrocyclics are synthesized, respectively, from monomers or condensation polymers by means of enzyme catalysts, the most frequently used of which is the esterase Candida antarctica lipase B. ${ }^{23,24}$

MCOs of engineering thermoplastics such as polycarbonates and aromatic polyesters have been known for a long time as their formation was observed during polymer manufacture. ${ }^{11} \mathrm{~A}$ great deal of systematic and thoroughgoing work for their syntheses and commercialization has been devised by Brunelle and co-workers at General Electric Corporation where they started in the late 1980s with the synthesis of bisphenol-A (BPA) cyclic oligomeric carbonates (CBPAC in the following). ${ }^{18}$ Notwithstanding the successes obtained with CBPAC, the ensuing polycarbonate materials present some issues difficult to overcome (see later in the text). Due to this, synthetic efforts were then moved towards polyester cyclic oligomers. Over the years, attention has been focused mainly on macrocycles of aromatic polyesters such as poly(ethylene terephthalate) (PET) and poly(butylene terephthalate) (PBT), their MCOs being indicated, respectively, as CET and CBT. ${ }^{11,14,25,26}$ In 1999 the $\mathrm{CBT}^{\circledR}$ technology passed to the Cyclics Corporation, under the tradename Cyclics ${ }^{\circledR} .{ }^{26}$ Some macrocycles are commercially available, such as pentadecanolide, hexadecanolide, and cyclodextrins. ${ }^{25}$ Most of MCOs need however to be prepared as for example those related to high-performance aromatic poly(ether ketone)s and poly(ether sulfone)s. ${ }^{25}$ More recently, attention has been focused on macrocycles achievable from bio-based building blocks, such as adipic, succinic and 2,5-furandicarboxylic acids combined with butanediol, hexanediol, di-O-2-(hydroxyethyl) resorcinol. ${ }^{27}$ Chart 1 reports examples of relevant MCOs. In the following CBT after EDROP will be referred to as $\mathrm{pCBT}$ (with a lowercase $\mathrm{p}$ ahead) to distinguish from conventional PBT obtained by classical polycondensation reaction. 


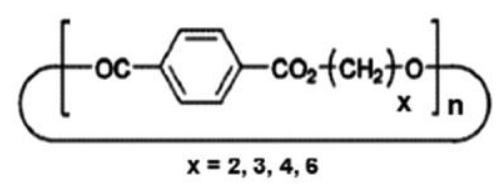

CET, CTT, СBT, CHT

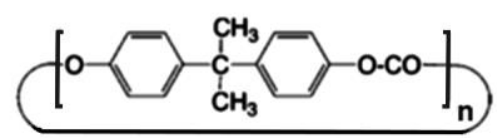

СBPAC

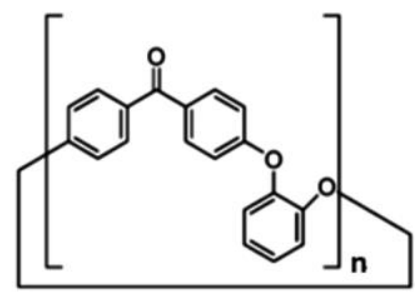

CAEK

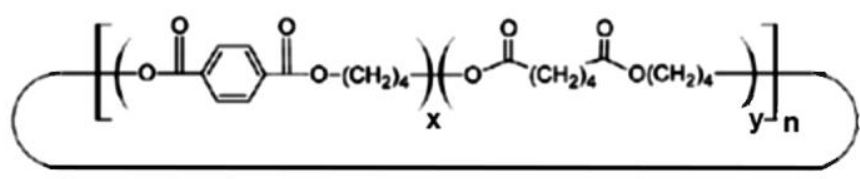

CBAT

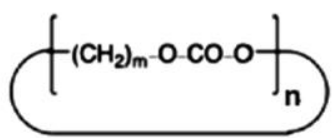

CAC

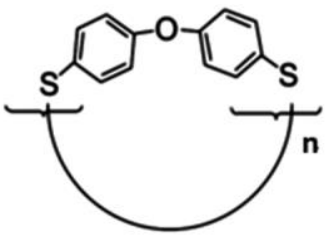

COBDS

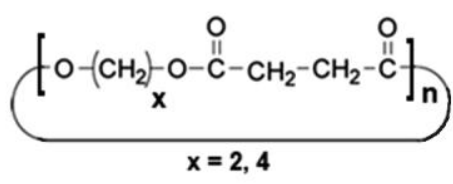

CES, CBS

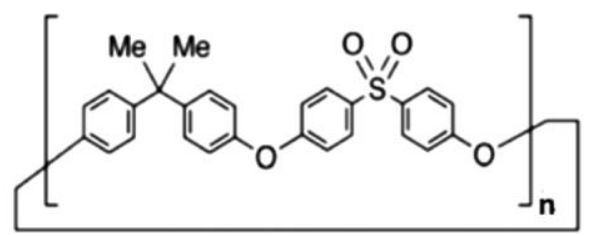

CAES

Chart 1. Some examples of MCOs.

In parallel with the advances in achieving MCOs through efficient methods, the typical features of ED-ROP ${ }^{14}$ appeared interesting for the exploitation of this synthetic tool in the huge and diversified field of science and technology of polymeric materials. ${ }^{5,6,28-30}$ The first virtue, much sought after today, of ED-ROP is that it is a solvent-free process, since conducting it, as preferable, in neat conditions, there is no need for solvents. Second, but not least is the fact that no small molecules, and hence no volatile by-products, are produced. Nominally MCOs have no end groups, however a small amount of end groups is necessary to initiate the reaction (see Scheme 1). Source of end groups can be purposely added catalyst, residual catalyst deriving from synthesis of MCOs, humidity, or traces of linear oligomers. Consequently, the number of end groups present in the system affects (together with other experimental parameters) the molecular weight of the linear polymer being formed. It is worth noting that conventional polycondensates with particularly high molecular weight are not so easy to be obtained, thus ED-ROP carried out in conditions of minimal concentration of end groups may represent an alternative to post-polymerization methods requiring vacuum and high temperatures. Moreover, being ED-ROP an equilibration process, the polydispersity index (PDI) obtained is usually around 2.0 (as for classical stepgrowth polymerization). Another aspect to consider is that the MCOs being strainless and their ring opening based on reshuffling of existing linkages, little or no heat is evolved during the ED-ROP process. This feature together with the fact that MCOs automatically ensure a perfect stoichiometric balance, make mixing of the reaction system not particularly important. This, in turn, candidates ED-ROP as a suitable method for high throughput (HTP) syntheses to achieve libraries of (co)polymers operating on small scale (50 to $100 \mathrm{mg}$ per reaction test). ${ }^{31}$ In practice, to ensure sufficient mobility to reach the equilibrium, during the ED-ROP reaction the temperature, at least for a brief time, should exceed the glass transition or, for semicrystalline polymers, the melting temperature of the polymer being formed. It is also worth noting that the MCOs, being homologous families of cycles of various sizes, have melting temperatures significantly lower than individual rings, and often also much lower than the parent polymer. For instance, PBT polymer melts around $225^{\circ} \mathrm{C}$ while its cyclic 
oligomers mixture starts to soften at about $140{ }^{\circ} \mathrm{C}$ and completely melts at $160-190{ }^{\circ} \mathrm{C} .{ }^{11,32}$ In some cases, however, the MCOs family is particularly rich in an individual cycle, which can even lead to melting temperatures higher than that of the parent polymer; this is the case of PET which melts around $255^{\circ} \mathrm{C}$ while its MCOs, highly rich in the cyclotrimer, melt in the range $270-300{ }^{\circ} \mathrm{C} .{ }^{32}$ It is evident that all the above-mentioned features make ED-ROP a useful synthetic tool in a variety of applications, often involving polymers and polymer-based materials of significant industrial interest.

Since the 1990s there has also been a flourishing of works on multicomponent polymeric materials, in particular polymer-based nanocomposites. ${ }^{33,34}$ Commonly speaking, the term "multicomponent" refers to blends, composites and nanocomposites, where it also corresponds to multiphasic materials. Here, we purposely extend the term also to copolymeric materials (not necessarily multiphasic), in relation to the fact that copolymers can be thought of as multicomponent from the constitutive point of view, being formed by comonomer units of different nature.

Indeed, copolymers are of considerable interest, both academic and industrial, because while many of their properties are often like those of the related homopolymers, they can also be significantly altered. ${ }^{35}$ Thus, $^{2}$ properties of technological relevance, such as glass transition, melting point, crystallinity, and solubility, can be tuned and suited to the specific intended use by properly introducing comonomeric units along the polymer backbone. Practically unlimited combinations of two (or more) repeat co-units give rise to several different sequences, extremes being block copolymers and alternating copolymers. In the field of addition polymers, random copolymers are largely diffuse, just mentioning the many commercial grades of polyethylene and polypropylene. ${ }^{36,37}$ As regards polycondensates, copolymers with co-units randomly distributed along the polymer chain are usually the end points of equilibrating systems. ${ }^{32,38}$

Melt blending of different polymers is one of the most important and relatively easy methods to obtain "new polymeric materials". Over $30 \%$ of commercial polymers worldwide produced are polymer blends. ${ }^{39-41}$ Apart from the valuable green aspect of being a solvent-free process, melt blending is largely used since two or more polymers, properly mixed in terms of composition and ensuing morphology, can lead to new materials endowed with modulated/improved properties thanks to a synergistic combination of those of the individual polymer components.

Another cost-effective and facile way of modifying polymers properties, in particular the structural ones, is compounding them with fillers or reinforcements of various nature and shape to get composite materials. ${ }^{42}$ Composite materials indeed offer combinations of different properties that cannot be simultaneously present in traditional materials such as metal alloys, ceramics and polymers. Polymeric matrix composites reinforced with high strength synthetic fibers (graphitic, aramidic and glass fibers), thanks to their lightness, excellent mechanical properties, flexibility in design and ease of manufacture, are widely used in a variety of applications (building, aircrafts, automotive, sporting). ${ }^{43}$ More recently, growing environmental concerns have pushed research towards the development of so-called eco-composites or bio-composites. These are composite materials consisting of natural fibers, such as wool or ligno-cellulosic fibers, embedded in polymeric matrices either produced from renewable sources or biodegradable, so that they can be easily degraded or bioassimilated with evident environmental and ecological advantages over conventional composites. ${ }^{44-46}$

A modern class of composites, that is polymer-based nanocomposites, in which the reinforcement embedded in the polymer matrix has at least one dimension in the nanometer range, have received enormous interest in the past three decades, starting from the boom of works on polymer/layered silicate nanocomposites in the 1990 s. $^{33,47}$ It must be said, that, after the first enthusiastic period, difficulties emerged in accomplishing high degrees of filler dispersion at the nanometric level, and, in turn, in achieving nanocomposite materials with the expected characteristics, e.g., excellent mechanical, barrier, electrical properties. This, combined with some 
drawbacks and health concerns about manipulation of nanopowders, partially modified the trend even though research perspectives in this field remain vast. ${ }^{34,48}$

For polycondensate systems the presence of non-negligible percentages of cyclic oligomers can affect the final properties of a given polymer material. For instance, cyclic oligomers, as already noted to be normally present in commercial polyesters, can migrate to the surface of their spun fibers and crystallize producing a surface "bloom" detrimental to subsequent dyeing. ${ }^{10}$ However, and interestingly, MCOs can modify the melt viscosity behavior of their parent polymers: the former indeed exhibit much lower melt viscosities with respect to the latter. Therefore, cyclic oligomers can be usefully added in minor amounts to intentionally lower the polymer melt viscosity during its processing without however affecting the final material properties, since, by raising the temperature, MCOs undergo spontaneous ring opening (the source of end groups being the admixed linear polymer chains) to give exactly the same macromolecules constituting the parent polymer. ${ }^{49}$

Over the past dozen years, ED-ROP and related topics have been discussed in several review works, some of them being of a general purpose, ${ }^{14,25}$ others focusing on the various polymerization techniques, ${ }^{50}$ such as the "cousin" entropically-driven ring-opening metathesis polymerization (ED-ROMP) process, ${ }^{51,52}$ others on applications of the resulting materials, ${ }^{51,53,54}$ reactivity of the most developed cyclic oligomers, i.e., cyclic butylene terephthalate, ${ }^{26,53,55}$ combination of CDP plus ED-ROP for polymer recycling, ${ }^{56}$ and ring opening of macrocyclic oligo esters obtained from renewable resources. ${ }^{27}$

In this review, the effectiveness of ED-ROP of MCOs as an efficient and versatile synthetic tool either to achieve multicomponent polymer materials (copolymers, blends, composites and nanocomposites) or facilitate their processing, compatibilization, properties modification or recycling is demonstrated through selected, representative examples, mostly taken from recent literature.

\section{Copolymer Synthesis through ED-ROP}

Many, if not most, of the examples of ED-ROP of strainless MCOs reported in literature (and eventually scaledup at industry level) are related to polyester-based materials. The transesterification reactions (linkages reshuffling) involved are generally catalyzed by metal-containing catalysts, typically di- $n$-butyltin oxide, tin octoate, distannoxanes, titanium tetraalkyloxides, or by organic bases or lipase enzymes. ${ }^{10,25,27}$ In the following description, examples of copolymer syntheses accomplished by ED-ROP are grouped into those leading to copolyesters and those leading to other types of copolymers.

\subsection{Copolyesters}

As already mentioned, ED-ROP features make this synthetic method perfectly suited to be applied in high throughput (HTP) syntheses to readily produce libraries of condensation polymers and copolymers. Adaption of classical polycondensations, such as those of polyesters like PET and PBT, to an HTP approach can indeed overcome many problems. A typical synthesis of PET from dimethyl terephthalate and ethylene glycol requires long reaction times, step-wise rising of temperature from about $220^{\circ} \mathrm{C}$ to more than $280{ }^{\circ} \mathrm{C}$, accompanied by continuous removal of methanol and/or excess glycol under reduced pressure $(0.3 \mathrm{~mm} \mathrm{of} \mathrm{Hg})$ and efficient stirring of an increasingly viscous reaction mixture. ${ }^{57}$ Moreover, when two monomers of the types A-A and B-B (as for PET and PBT) or other comonomer mixtures (to prepare a copolymer of a given composition) are involved, it is crucial to preserve a very accurate stoichiometric balance between reactants.

Kamau et al. demonstrated ED-ROP method as a valuable and convenient HTP synthetic tool producing several series of copolyesters derived from aliphatic or aromatic acids and alcohols at variable comonomer 
ratios and in high yield on a scale of ca. $90 \mathrm{mg} .{ }^{31}$ The synthetic procedure involved heating mixtures of macrocyclic oligoesters in the appropriate ratio at $250-300{ }^{\circ} \mathrm{C}$ for $2 \mathrm{~h}$ under neat conditions and in the presence of suitable transesterification catalysts $(0.1 \mathrm{~mol} \%)$. Obtained molecular weights were generally higher than $25000 \mathrm{~g} / \mathrm{mol}\left(M_{\mathrm{w}}\right)$ and PDI values close to 2.0 .

This approach has the potential to be exploited also for the HTP polymer synthesis of polycarbonates, polyamides, polyurethanes, high performance aromatic polymers, and olefin-containing polyesters and amides, syntheses of all these polymers having been achieved successfully by ED-ROP or ED-ROMP.

One might infer that an even simpler alternative to this ED-ROP-based HTP approach to copolyesters could be the mixing the two homopolyesters (or a concentrated solution of them) to react them together in the presence of a suitable catalyst. However, in a later work comparing ED-ROP of cyclic CET and cyclic oligo(trimethylene terephthalate) (CTT) mixtures to melt blending of the corresponding PET and poly(trimethylene terephthalate) (PTT) homopolymers, ${ }^{32}$ it was demonstrated that the homopolymers do not mix well, neither neat nor in concentrated solution, and, consequently, they react together very slowly. Moreover, if the transesterification reaction is incomplete, the formed copolymers may not have the desired composition and separating them from any unreacted homopolymers, may be much more difficult than separating MCOs from polymers. It must be said that even with ED-ROP too short reaction times can lead to blocky copolymeric products, needing the system some time to become random, as testified by a thorough NMR analysis $^{31,32}$ and confirmed by a later study of Martínez de llarduya and Muñoz-Guerra. ${ }^{38}$

A similar approach was used to prepare by ED-ROP a series of aromatic-aliphatic copolyesters, namely poly(hexamethylene terephthalate)-co-(p-dioxanone), PHT-co-PDO, within a range of aromatic (HT) to aliphatic (DO) units ratios from 9 to $1.3 .^{58}$ Also in this case the compositional and microstructural features of the obtained copolyesters were determined by an accurate NMR analysis, which gave evidence of their random nature. Copolyester compositions deviated from those used in the feed as a consequence of the tendency of PDO to give back depolymerization, even though the ring opening of the MCOs mixture, carried out at temperatures notably lower than those required for conventional polycondensation, minimizes this phenomenon, which for PDO is known to begin above its melting temperature. These copolyesters were sensitive to hydrolytic degradation, which was observed to take place superficially with the generation of non-water-soluble degraded fragments and release of water-soluble dioxanoic acid to the aqueous medium.

In another work, ${ }^{59}$ ED-ROP (even if the authors referred to it simply as ROP and did not cite any work of the vast literature of reference) was in fact exploited as efficient route to high-molecular-weight poly(butylene succinate) (PBS) and to achieve block copolymers of PBS with polyethylene glycol (PEG). A macrocyclic lactone consisting of butylene succinate dimer (BSD) was indeed successfully isolated from oligomeric by-products of PBS prepared by classical polycondensation. BSD, which being constituted by 20 skeletal atoms is to all effects a strainless ring, was subjected to ring-opening polymerization in the presence of tin octoate as the catalyst to obtain PBS with a number-average molecular weight close to $10^{5} \mathrm{~g} / \mathrm{mol}$, that is much higher than that of the PBS obtained by classical polycondensation. When the (entropically-driven) ROP of BSD was performed in the presence of PEG or its monomethyl ether (Me-PEG) as the macro-initiators, triblock (PBS- $b$-PEG- $b$-PBS) and diblock (Me-PEG- $b$-PBS) copolymers were respectively obtained, even though the yields and also the molecular weights were lower compared to the PBS homopolymer. The exploitation of the BSD macrocycle can therefore allow the synthesis of various PBS-based copolymers having controlled structures and properties, interesting, e.g., for biomedical applications.

The ED-ROP method was proven to be an excellent tool in an interesting paper of Morales-Huerta et al. ${ }^{60}$ where the glass transition temperature $\left(T_{\mathrm{g}}\right)$ of poly(alkylene succinate)s, namely PBS and poly(ethylene succinate) (PES), was modulated by inserting aromatic co-units (diol and diacid) of bio-based origin via ring- 
opening copolymerization. As shown in Scheme 3, two series of random aliphatic-aromatic copolyesters derived from succinic (S) and 2,5-furandicarboxylic (F) acids, and from di-O-2-(hydroxyethyl) resorcinol (R) as diol substituent of either 1,4-butanediol $(B)$ or ethylene glycol $(E)$, respectively, were obtained in very good yield by ED-ROP performed in bulk and catalyzed by $\mathrm{Sn}(\mathrm{Oct})_{2}$. Besides showing good thermal stability with onset of degradation close to $300^{\circ} \mathrm{C}$, these resorcinol-containing succinate-furanoate copolyesters are amorphous, their $T_{\mathrm{g}}$ increasing monotonically with the content in resorcinol for both series in the range from -30 or from $-13{ }^{\circ} \mathrm{C}$ for $\mathrm{B}$ - or E-based copolyesters, respectively, up to around $45^{\circ} \mathrm{C}$ (see the $T_{\mathrm{g}}$ vs. composition plot inserted in Scheme 3). Nevertheless, it was observed that the substitution of the alkanediols by resorcinol does not repress the biodegradability of the ensuing copolyesters but it is even enhanced in the case of 1,4butanediol. The copolyesters showed appreciable hydrolytic degradation when incubated for a few weeks in physiological saline, this behavior being enhanced in the presence of lipases.

In the following some recent examples exploiting ED-ROP coupled to other processes which enlarge its scope and the possibility of obtaining copolymers with specific characteristics are presented.

A quite common variant of ED-ROP is the already mentioned ED-ROMP, which involves polymerization through an olefin-metathesis of olefin-containing macrocyclic monomers under entropically favorable conditions. This technique allows for the preparation of polymers with unique backbone functionality, with prethreaded supramolecular guest molecules, and with well-defined sequences. ${ }^{51,52}$

ED-ROMP of macrocyclic olefins containing the deoxycholic acid moiety to give functionalized polymers and copolymers was reported by Hodge and Chakiri. ${ }^{61}$ Three new families of macrocyclic olefins were prepared from deoxycholic acid. Two of these have a novel structure where the bile acid unit is linked to a C20 fatty acid unit via the $3 \alpha$ - and $12 \alpha$-positions, thus creating macrocycles with rings with a repeat unit of 29 ring atoms. Their ED-ROMP resulted in polymers with free hydroxyl groups, or free methyl or $t$-butyl carboxylic ester groups. The latter could be converted into carboxylic acid groups by treatment with trifluoroacetic acid. The polymers form transparent films that are potentially useful for supporting cell growth; indeed, the free hydroxyl or carboxylic acid groups on film surface can potentially be chemically modified in various ways. 


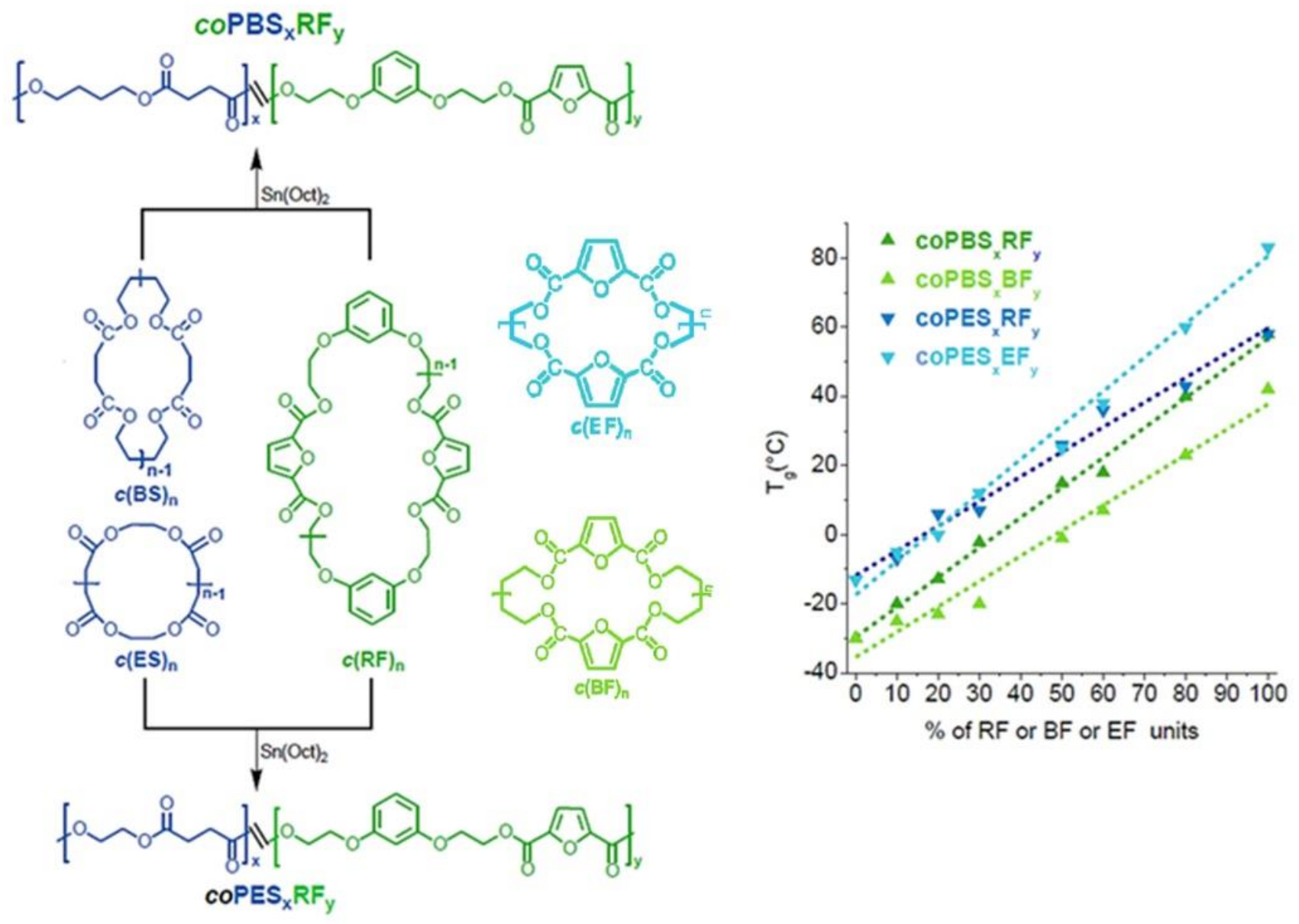

Scheme 3. Route of syntheses leading to PBSRF and PESRF copolyesters and $T_{\mathrm{g}}$ of furanoate-succinate copolyesters as a function of composition. Adapted from ref. 60.

A so-called "green cascade" polycondensation-coupling ring-opening polymerization (PROP) method for the facile synthesis of sustainable poly(butylene-co-decylene terephthalate) (PBDT) copolymers was reported by Xu et al. in a recent work. ${ }^{62}$ The PROP method allows the incorporation of diols into polyesters, with no need for vacuum (as required in classical polycondensation) and with high atom economy, ${ }^{63}$ typically greater than $90 \%$. Utilizing CBT as macrocyclic monomers and bio-based 1,10-decanediol as initiator, PBDT copolyesters were synthesized and their microstructures assessed by 1D and 2D NMR analyses. Property investigations of the PBDT copolyesters revealed that $T_{\mathrm{g}}, T_{\mathrm{m}}$, storage modulus and Young's modulus decrease while the toughness increases, by increasing the decanediol content. Thus, the introduction of bio-based decanediol in PBT, providing lower processing temperature and better toughness for copolyesters compared to PBT homopolymer, could be of potential interest for applications in the fields of beverages and plastic packaging.

Behaving as "polyethylene-like" materials, aliphatic polyesters embedding long methylene chain may represent a "green" alternative to traditional thermoplastics. They can be prepared by exploiting ED-ROP of macrolactones. In a recent work, ${ }^{64}$ the copolymerization of two large size lactones, namely the $\omega-6$ hexadecenlactone $(6 \mathrm{HDL})$ and $\omega$-pentadecalactone and that of these two macrolactones with $\varepsilon$-caprolactone $(\mathrm{CL})$ were successfully achieved in the presence of a pyridylamidozinc(II) complex. High turnover frequencies were observed for the $\mathrm{CL}$ polymerization, while for the macrolactones an entropy-driven behavior was recognized. The random microstructure of the achieved copolymers was ascertained by NMR and MALDI 
analyses, which also showed formation of cyclic oligomers, reasonably due to backbiting processes, which are quite frequent in the ROP of macrolactones. The melting temperatures as well as the thermal and thermooxidative degradation behavior were dependent on the copolymer composition. The poly(6HDL-co-CL) and poly(PDL-Co-CL) copolymers showed a two-step degradation behavior, which could be nicely correlated to relative content of the two comonomers.

Sustainable aliphatic polyesters with tunable thermal and mechanical properties were obtained by Hillmyer and co-workers through the synthesis of copolymers by entropically-driven ring-opening transesterification polymerization (ROTEP) of macrolides using titanium isopropoxide as an inexpensive and nontoxic catalyst. ${ }^{65}$ Two 14-membered macrolides were reported: a cyclic tetraester with alternating lactic acid (LA) and 3hydroxypropionic acid (3HP) units and a cyclic diester with alternating glycolic acid (GA) and 2-methyl-1,3propanediol (2MD) units. ROTEP of these macrolides, yielding poly(LA-stat-3HP) and poly(GA-alt-2MD) respectively, were found to be modestly endothermic $\left(\Delta H_{\mathrm{p}} 2.0\right.$ and $0.5 \mathrm{~kJ} / \mathrm{mol}$, respectively) and endoentropic $\left(\Delta S_{\mathrm{p}} 27\right.$ and $23 \mathrm{~J} / \mathrm{mol} \mathrm{K}$, respectively). Titanium isopropoxide functioned as an active catalyst giving conversions higher than $90 \%$ in less than $1 \mathrm{~h}$. Poly(GA-alt-2MD) showed amorphous behavior with a low $T_{\mathrm{g}}\left(-30{ }^{\circ} \mathrm{C}\right)$ while poly (LA-Co-3HP) showed $T_{\mathrm{g}}$ values up to $13^{\circ} \mathrm{C}$ and, depending on the regioregularity, also a melting temperature up to $96^{\circ} \mathrm{C}$.

An emerging synthetic technique, namely segmer assembly polymerization (SAP), has been recently reviewed as a method to achieve precision aliphatic polyesters. ${ }^{66}$ In principle SAP allows the synthesis of an envisioned polyester starting from pure linear or (macro)cyclic monomers arranged in a defined primary sequence, as in the case of a biomacromolecule. Thus, through a bottom-up approach, the macroscopic properties of a biodegradable polymer (e.g., an aliphatic polyester) are determined by microstructural control. An example of precision synthesis of aliphatic copolyesters via SAP is ED-ROMP. Weiss et al. ${ }^{67}$ employed EDROMP as a general approach to synthesize sequence-controlled copolymers bearing glycolic, lactic and caprolactic acid units. As shown in Scheme 4, ED-ROMP of macrocycles containing a specific sequence followed by hydrogenation readily generated saturated periodic polyesters. This approach should be applicable to any macrocycle bearing an internal alkene moiety. However, structurally asymmetric monomers are generally unsuitable due to the loss of sequence regularity.
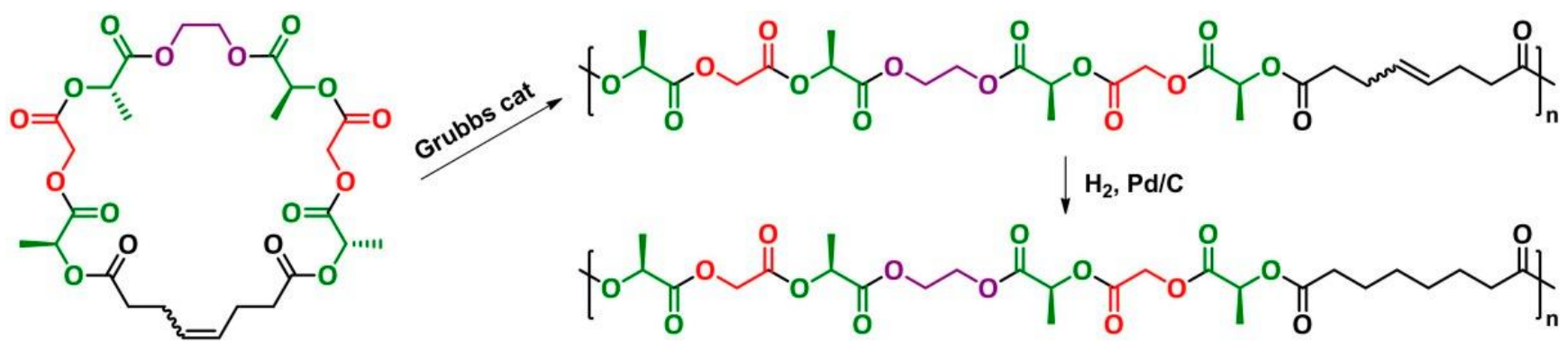

Scheme 4. Sequence-controlled aliphatic copolyesters prepared via ED-ROMP. ${ }^{66}$

Nowalk et al. ${ }^{68}$ described the synthesis of sequence-defined copolyesters prepared by ED-ROMP of strainless cyclic macromonomers embedding monomer sequences of lactic, glycolic, 6-hydroxy hexanoic, and syringic acids. The incorporation of ethylene glycol and metathesis linkers facilitated synthesis and provided the olefin functionality needed for ED-ROMP. Cyclic macromonomers were prepared using both ring-closing metathesis and macrolactonization reactions. Polymerization produced sequence-defined polymers with controlled molecular weights on a multigram scale. To further enhance molecular weight control, the 
macromonomers were prepared with cis-olefin moieties in the metathesis-active segment. Interestingly these selectivity-enhanced (SEED-ROMP) polymerizations exhibited first-order kinetics and narrow dispersities were observed. The effect of catalyst initiation rate on the polymerization was investigated. The living character was further demonstrated through the preparation of block copolymers. Computational analysis suggested that the enhanced polymerization kinetics were due to the cis-macrocyclic olefin, less flexible and with a larger population of metathesis-reactive conformers. It is worth noting that SEED-ROMP can not only be used for the synthesis of polyesters, but it represents a general method for incorporation of sequenced segments into molecular weight-controlled polymers.

\subsection{Other copolymers}

As already mentioned, ED-ROP can be a useful method also for synthesizing polycondensates other than polyesters. A few examples regarding copolymers based on polycarbonates or poly(ether ketone)s are here presented.

Hodge et al. ${ }^{69}$ reported on the CDP in solution of poly(bisphenol-A carbonate) and two poly(alkylene carbonate)s to prepare mixtures of MCOs then copolymerized by ED-ROP to achieve carbonate-carbonate and carbonate-carboxylate ester copolymer libraries. A HTP approach was indeed used, carrying out the ED-ROP reactions on a small-scale and testing various catalysts. The authors observed that aromatic carbonates were less reactive than the aliphatic ones and that tetra- $n$-butylammonium tetraphenylborate was the most generally useful catalyst of those investigated. The aliphatic carbonate-containing MCOs underwent ED-ROP at about 230 ${ }^{\circ} \mathrm{C}$, even in the absence of added catalyst. Copolymerizations of the carbonate-containing MCOs, both with each other and with carboxylate ester-containing MCOs were investigated. These provided in high yields (> 84\%) a range of copolymers, which were shown by ${ }^{13} \mathrm{C}$ NMR analysis to have the repeat units in proportions close to the feed MCOs ratios and almost always in random sequences. The authors also pointed out that the thermal sensitivity of the poly(alkenyl carbonate)s discouraged the use of more vigorous reaction conditions.

Conventionally, polycarbonate is obtained from the polymerization of BPA with highly toxic phosgene or diphenylcarbonate, in turn derived from dimethylcarbonate or phosgene, ${ }^{70}$ which poses environmental and health concerns. Moreover, despite the commercially viable processes for synthesis, polymerization, and processing of CBPAC, a major issue which could not be overcome was the lack of solvent-resistance of the polycarbonate materials. Techniques were developed for preparation of either semicrystalline or lightly crosslinked materials; however, they did not meet the specifications required for automotive or aeronautic applications. ${ }^{11}$ Most of the efforts on PC cyclics were then shifted toward polyester cyclic oligomers.

Nevertheless, remaining in the class of polycarbonates, a recent interesting work described the synthesis of main chain sulfur-containing aliphatic homo- and copolycarbonates by organocatalytic ring-opening polymerization of macrocyclic carbonates. ${ }^{71}$ Main-chain thioether functionalized aliphatic polycarbonates (APCS) combining the reactive oxygen species (ROS) responsiveness of thioether groups and biodegradability of APCs can have potential high-value biomedical applications. Among several commercial organocatalysts tested, triazabicyclodecene (TBD) was demonstrated to effectively activate, in the presence of benzyl alcohol as the initiator, the ED-ROP of macrocyclic carbonates containing thioether groups. Moreover, TBD catalyst exhibited high activity in mild conditions and living polymerization character, as evidenced by kinetic studies and chainextension reactions. Tailor-made thioether-functionalized APCs with high end-group fidelity, high molecular weight and PDI < 1.3 were thus achieved. On one hand, tunable thermal properties were obtained via copolymerizations with other cyclic monomers, such as trimethylene carbonate, $\mathrm{CL}$, valerolactone and lactide. On the other hand, improved hydrophilicity for biomedical applications, was accomplished by using PEG and mPEG to initiate ROP (instead of benzyl alcohol) and give, respectively, A-B-A triblock and A-B diblock 
copolymers with high conversion rates, predictable molecular weights and low PDI. Such amphiphilic block copolymers could assemble into nanoparticles suitable as ROS-responsive drug delivery vehicles.

ED-ROP was also proven to be useful for preparing high-performance thermoplastics such as fully aromatic poly(ether sulphone)s (PAES), poly(ether ketone)s (PAEK) and poly(ether ether ketone)s (PEEK). ${ }^{25}$ These classes of polymers are known as high-performance thermoplastics and are used in a wide range of demanding applications, from the automotive and aerospace industries to dentistry and microelectronics, where their excellent thermal, mechanical and environmental stability are suitable. ${ }^{72}$

More than a dozen years ago, an imaginative method was reported in a study of Yue et al. to prepare fully aromatic PAEK bearing macrocycle pendants and then achieve the corresponding thermosets by crosslink via ED-ROP of the pendant cycles. ${ }^{73}$ First the cyclization of $2^{\prime}, 5^{\prime}$-dimethoxy[1,1'-biphenyl]-2,5-diol and a difluoro monomer was carried out under pseudo-high dilution conditions to give a macrocycle aryl ether ketone bearing two reactive hydroxyphenyl groups. Fully aromatic PAEK with macrocycles pendant from the main chain were then successfully prepared by copolymerization via a nucleophilic reaction of the above-mentioned macrocycle, 4,4'-(hexafluoroisopropylidene)diphenol, and 4,4-difluorobenzophenone in various proportions. The obtained copolymers had high molecular weights, good solubility, and high glass transition temperatures. Subsequent crosslinking reaction of the copolymers by ED-ROP in the presence of a basic initiator (CSF) afforded fully aromatic thermoset PAEKs (Scheme 5). The crosslinked PAEKs showed much higher $T_{\mathrm{g}}$ values, excellent thermal stability $\left(>500^{\circ} \mathrm{C}\right)$ as well as better modulus and mechanical strength than the corresponding linear copolymers.

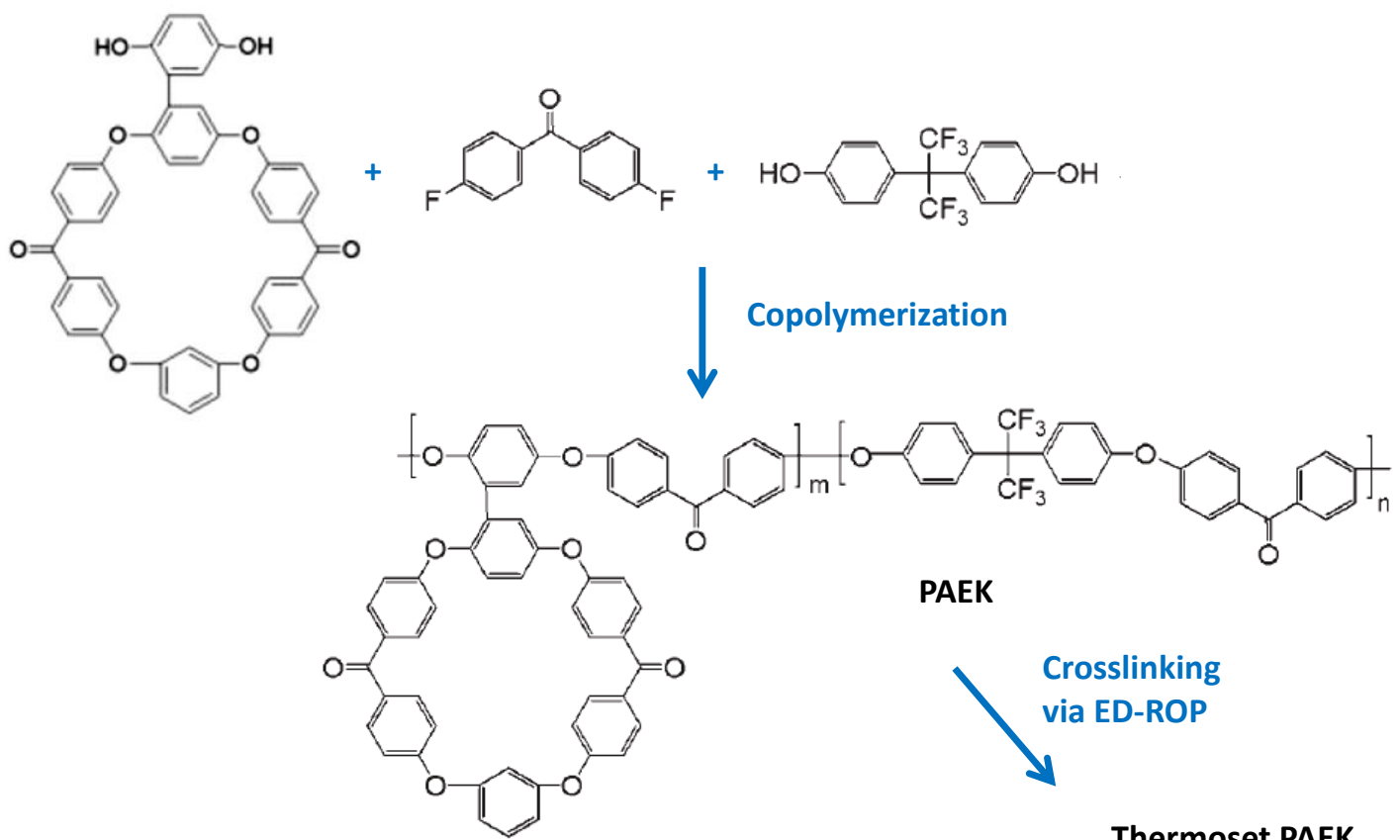

Scheme 5. Synthetic route to PAEK copolymer thermosets. Adapted from ref. 73.

Aricò and Colquhoun very recently reported on the synthesis, characterization and ring-opening polymerization of two new families of catechol-based macrocyclic aromatic ether-sulfones. ${ }^{74}$ Cyclocondensation carried out in pseudo-high dilution conditions between 4,4-bis(4-chlorobenzenesulfonyl)biphenyl and catechol led to the isolation of four novel ether-sulfone macrocycles (cyclic dimer, -trimer, -tetramer and -pentamer). Similarly, cyclocondensation of catechol with a novel seven-aromatic-ring diketone/disulfone monomer allowed the isolation of the two new aromatic ether-ketone-sulfone macrocycles (cyclic monomer and -dimer). Given the industrial 
relevance of poly(ether sulfone)s, ED-ROP of one of the new macrocycles was studied by the authors using a catalytic amount of cesium fluoride as initiator. The resulting poly(ether sulfone) showed good solubility, indicating absence of cross-linking, and an inherent viscosity comparable to values for commercially available poly(ether sulfone)s, indicating high molecular weight.

In another interesting work, Behrendt and Schlaad demonstrated the effectiveness of transition metal-free entropy-driven disulfide metathesis polymerization of unsaturated L-cystine-based macrocycles for the synthesis of high-molecular-weight heterofunctional poly(disulfide)s, i.e., poly(ester disulfide alkene) and poly(amide disulfide alkene). ${ }^{75}$ The investigated disulfide metathesis polymerization proceeded rapidly reaching equilibrium within 1-5 min (with monomer conversion 70-90\%) in polar aprotic solvents, such as $N, N$ dimethylacetamide, dimethylsulfoxide, or $\gamma$-valerolactone. Thiol-terminated polymers are stable in bulk or when dissolved in weakly polar solvents, but rapidly depolymerize in dilute polar solution. Undesired depolymerization can be largely avoided by efficient end-capping of the polymer thiol end group with iodoacetonitrile. The disulfide metathesis polymerization can be considered as a "green" method which should be generally applicable to a large variety of disulfide-containing macrocycles with sequenced functionalities, different ring sizes, thus offering the possibility to access degradable poly(disulfide)s with adjusted functionalities and properties for applications, e.g., as responsive materials for biomedical applications.

\section{ED-ROP for Polymer Blends, Composites and Nanocomposites}

Academic and industrial interest in multicomponent polymer-based materials, such as blends, composites and nanocomposites, continues to grow rapidly because they can replace traditional materials in many applications, such as automotive, construction, naval, aerospace, food packaging. ${ }^{40,41,43,45,48}$

In this arena, MCOs and their ED-ROP reaction could represent an alternative, interesting approach particularly appealing for processing high-temperature-melting engineering thermoplastics and improving phase compatibility in (nano)composites and blends. Indeed, MCOs are relatively low-cost starting materials, possess a very low (water-like) melt viscosity, hence can be processed at much lower temperatures compared with the corresponding high-molecular-weight polymers, and can be readily polymerized without emission of volatiles (thus zeroing the formation of voids) upon heating under relatively mild conditions. ${ }^{14,25}$

Regarding the field of polymer blends, ED-ROP of MCOs has been used to improve the phase miscibility/compatibility and hence obtaining materials with stable morphologies and enhanced properties, not only with respect to those of the two (or more) individual components but even to those of the blend without added macrocycles. The in-situ polymerization of low viscosity cyclic oligomers has been investigated in the fabrication of polymer composites to overcome many of the processing problems of liquid resin composite molding techniques. Indeed, MCOs have the low viscosity necessary for making composite binders via melt infusion and are capable of rapid polymerization and crystallization at the processing temperature. The low viscosity of the molten cyclic oligomers has been also applied in polymer nanocomposites to improve the nanofiller distribution/dispersion and the nanofiller-polymer matrix interaction. Selected examples concerning the exploitation of MCO/ED-ROP advantages for these applications are reviewed in the following.

\subsection{Blends}

In the early 2000s, Tripathy et al. ${ }^{76}$ prepared miscible pCBT/PVB (poly(vinyl butyral)) blends at various compositions exploiting the in-situ ED-ROP of CBT oligomers during melt blending in the presence of PVB polymer and a stannoxane initiator. The $\mathrm{PCBT} / \mathrm{PVB}$ reactive-blended materials were characterized by a variety 
of techniques and their properties compared with those of physically-melt-blended conventional PBT and PVB homopolymers. It was found that the in-situ prepared pCBT/PVB blends show evidence of miscibility, such as appearance of a single $T_{\mathrm{g}}$ and suppression of PBT crystallinity. In contrast, the conventional PBT/PVB blends showed incompatibility. The cause of miscibility in the in-situ prepared PCBT/PVB blends was ascribed to the formation of a graft copolymer, as testified by FTIR and NMR analyses. These results demonstrate that there are unique possibilities for modifying the miscibility behavior of polymer pairs of applicative interest by combining polymerization of strainless cyclic ester oligomers with polymer melt blending.

In another work, ${ }^{77}$ a series of polypropylene/polycarbonate (PP/PC) blends were prepared by in-situ polymerization and compatibilization via anionic ED-ROP of macrocyclic CBPAC in the presence of a pre-melted maleinized PP (MPP) matrix. The so-achieved blends exhibited a number of special properties over traditional polymer blends and homopolymers. A surface-active compatibilizer, i.e, pCBPAC grafted onto a mPP backbone generated in situ, resulted in micro- and nanostructured polymer blends consisting of a pCBPAC minor phase and a MPP major phase. By varying the processing conditions, in particular composition and mixing temperature, it was possible to reduce the size of the PCBPAC ellipsoidal dispersions up to an average minor diameter of 150 $\mathrm{nm}$. NMR and TEM characterizations indicated that the PCBPAC dispersions do not appreciably influence crystal content in the PP phase. Overall results highlighted a simple strategy and versatile route to new polymeric materials with enhanced performance.

In-situ ED-ROP of CBT in the presence of molten poly(ethylene-co-vinyl acetate) (EVA) copolymer was exploited with the aim of preparing EVA/pCBT nanostructured blends by Bahloul et al. ${ }^{78}$ The ring-opening polymerization of $\mathrm{CBT}$ was initiated by titanium phenoxide $\mathrm{Ti}(\mathrm{OPh})_{4}$. Due to the aromatic character of this titanium derivative, the transfer reaction of the living PCBT chains onto the EVA backbone was enhanced (compared to the more classical aliphatic titanium systems), thus leading to formation of an EVA- $g$-pCBT copolymer. The graft copolymer, formed in the percentage of about $11 \%$ by weight, was characterized by ${ }^{1} \mathrm{H}$ NMR after selective extraction from the blend. Blend morphology observed by TEM showed, as desired, a fine dispersion of pCBT phase with spherical domains ranging from 100 to $500 \mathrm{~nm}$ in diameter (domains appeared more ellipsoidal upon compression molding for characterization) stabilized by the presence of the graft copolymer which acts as an in-situ formed compatibilizer. This led to improved rheological and mechanical properties, in particular the tensile strength.

As it will be discussed later, in-situ ring-opening of CBT to give $\mathrm{PCBT}$ has been extensively used for processing of fiber-reinforced composites in place of thermosetting polymers, as well as for fabrication of nanocomposites to enhance the nanofiller dispersion. However, $\mathrm{PCBT}$ often results in too brittle materials due to the formation of large, highly perfect crystals with a lack of inter-crystalline tie molecules. To overcome this problem, Abt et al. ${ }^{79}$ studied the role of different isocyanates on the ring-opening polymerization of CBT during reactive melt blending with the aim of obtaining isocyanate-toughened pCBT blends and evaluating their properties. CBT were reacted in a batch mixer with three types of isocyanate: namely, bifunctional aromatic 4,4'-methylenebis(phenyl isocyanate) (MDI), bifunctional aliphatic hexamethylene diisocyanate (HDI) and a polymeric aromatic isocyanate (PMDI). They observed that using amounts from 0.5 to $1 \mathrm{wt} \%$ isocyanate led to a dramatic increase in elongation at break of ensuing modified pCBT, from 8 to above 100\%, while stiffness and strength of the modified pCBT decreased by about $10 \%$. The isocyanate-modified samples showed a considerable torque increase compared to unmodified CBT, because of chain extension. NMR analysis showed that the formation of thermally stable amide groups is the dominant chain extension reaction mechanism. Melting and crystallization temperatures as well as degree of crystallinity were found to decrease with increasing isocyanate content. Both chain extension and decrease in crystallinity were proposed to account for the toughening effect of isocyanates. 


\subsection{Composites}

A polymer-based composite is a material composed of short or continuous fibers (glass, carbon, aramid, or natural fibers) or micrometric inorganic particles (e.g., calcium carbonate, talc, silica, carbon black) bound together by a polymeric matrix which can be a thermoset or a thermoplastic. Since the first applications dating back to over a century ago, polymer-based composites have been increasingly used in civil and industrial engineering applications because they provide lightweight and cost-effective alternatives to conventional materials. ${ }^{43,45}$

ED-ROP of cyclic oligomers (prevalently obtained from polyesters) has been recently extensively explored for the preparation of thermoplastic composite materials. The low, if not null, exothermicity of this (entropicallydriven) reaction and the water-like melt viscosity of MCOs are indeed beneficial to obtain a much more uniform distribution of material properties. High injection speeds at low injection pressures can be applied during the injection process minimizing the risk of fiber preform displacement/distortion in the mold and favoring a homogeneous fiber impregnation.

A detailed review of representative results achieved by exploiting ED-ROP in the preparation of composites containing traditional (glass and carbon) or natural fibers or particulate microfillers is reported in the following. 3.2.1. Traditional fiber-reinforced composites. Fiber-reinforced thermoplastic composites (TPCS) offer several interesting advantages over their thermosetting counterparts like a higher toughness, faster manufacturing, and possibility of recycling, being grindable into fine particles and in turn injection moldable (together with virgin polymer) into new short fiber-reinforced parts. ${ }^{42,43}$

In structural applications, alternating layers of fiber textiles and polymer sheets are stacked by melt processing in-between the plates of a hot press to incorporate high volume fractions of fibers and tailor the load bearing capacity of the final material through fiber lay-up. However, this fabrication process requires high processing temperatures and pressures due to the high melt viscosity of the thermoplastic matrix and often results in products with insufficient fiber impregnation and high void content. On one hand, to improve these aspects, various semi-finished products have been developed such as co-mingled textiles constituted of both reinforcing and polymer fibers, textiles made of powder coated fibers and partially or fully consolidated panels (semi-pregs and pre-pregs). On the other hand, these operations raise products prices and limit parts in size and thickness.

An alternative and cheaper solution is to exploit reactive processing: ${ }^{80}$ after impregnating the fibers with low-viscosity mono- or oligomeric precursors, their polymerization is conducted or completed in situ. Reactions can be initiated by heat or UV radiation and might require the addition of a catalytic system prior to impregnation. Due to their low molecular weight, polymer precursors have much lower melt viscosities and better fiber impregnation is therefore achieved without the need for high processing pressures. Ring opening polymerization of cyclic monomers ( $\varepsilon$-caprolactam, L-lactide), macromonomers/MCOs (laurolactam, CBT) or epoxy moieties borne by linear oligomeric precursors (bisphenol-A diglycidyl ether oligomers) as well as vinyl polymerization of unsaturated monomers/oligomers (methyl methacrylate or analogues) are generally employed.

When ED-ROP of polyester macrocycles is exploited for the reactive processing of fiber-reinforced TPCs, differently from other polymerization methods which being exothermic can lead to non-uniform distribution of properties, practically no heat is generated, this affording more uniform and improved material properties. ${ }^{81-85}$ Moreover, the water-like melt viscosity behavior of MCOs makes them advantageous ingredients for polymermatrix composite materials when using compression molding, pultrusion, injection molding, and liquid composite molding (LCM) techniques. ${ }^{80}$ The last are techniques, such as thermoplastic resin transfer molding (TP-RTM), structural reaction injection molding (SRIM), vacuum-assisted resin infusion (VARI), and resin film 
infusion (RFI), which are similar to pre-preg production for thermoset composites but use pre-preg hand lay-up. MCO-impregnated pre-pregs can be prepared by either dispersing MCOs powder on the fibrous reinforcement or by soaking it in a solution of dissolved macrocycles with subsequent solvent evaporation. Furthermore, the very low melt viscosity of cyclic oligomers allows the use of molten MCOs at high injection speeds and low injection pressures, thus minimizing fiber preform displacement or distortion in the mold, and subsequent EDROP reaction completion in the mold maintained at high temperatures.

As thoroughly reviewed by Abt and Sanchez-Soto, ${ }^{26}$ CBT macrocycles have been extensively investigated in academic and applicative research for the preparation of fiber-reinforced TPCs because of their low melting temperature $\left(\sim 160{ }^{\circ} \mathrm{C}\right)$, low viscosity $\left(0.02 \mathrm{~Pa} s\right.$ when heated above $150{ }^{\circ} \mathrm{C},{ }^{83}$ good mechanical properties, usefulness in various applications, and commercial availability. Composites based on pCBT and glass fibers (GF), ${ }^{26,84}$ and carbon fibers (CF), ${ }^{26,83,85,86}$ either as unidirectional fibers or woven fabrics, are considered in the following.

GF-based materials have been prepared in the presence of tin-based transesterification catalysts by vacuum-assisted and thermoplastic RTM as well as compression molding, with better results achieved if the molding occurred under pressure-controlled conditions. ${ }^{26,87}$ Catalyst type and content, polymerization temperature, and GF surface modification have significant effects on the molecular weight and degree of crystallinity of the polymerized pCBT. By conducting ED-ROP reactions of CBT at $190^{\circ} \mathrm{C}$ for 30 min in the presence of butyltin chloride dihydroxide, the obtained high reaction rate resulted in a short induction time, and hence in a small window for fiber impregnation: ${ }^{26,84,81}$ about $2 \mathrm{~min}$ at $180{ }^{\circ} \mathrm{C}$ and less than $1 \mathrm{~min}$ at $190{ }^{\circ} \mathrm{C}$. Optimal induction times should be controllable in a window of minutes (e.g., $5 \mathrm{~min}$ ) which are necessary to manufacture large-scale composite parts by LCM processes. Butyltin tris(2-ethylhexanoate) with low catalytic activity was tested by Yan et al. ${ }^{84}$ for the preparation via vacuum-assisted RTM of pCBT/GF composites containing 11 layers of plain-woven fabrics of GF. The CBT polymerization was carried out for $1 \mathrm{~h}$ under nitrogen atmosphere by varying the polymerization temperature from 180 to $210{ }^{\circ} \mathrm{C}$. The composites prepared with $0.5 \%$ catalyst at 190 ${ }^{\circ} \mathrm{C}$ resulted those with the best mechanical properties. Zhang et al. ${ }^{87}$ explored the influence of temperature on flexural properties of pCBT/glass fabric laminates and their fusion-bonded joints obtained by combining vacuum-assisted RTM and compression molding. The catalyst was adsorbed onto the fabric surface by dissolution in isopropanol followed by drying prior CBT injection in the mold. ED-ROP was then carried out for 20 min applying $4 \mathrm{MPa}$ and testing different temperatures. That optimal for CBT polymerization was found at $230^{\circ} \mathrm{C}$ and that for crystallization of pCBT was $191^{\circ} \mathrm{C}$. The achieved composite laminates with groove coupling were then butted and heated to $240^{\circ} \mathrm{C}$ in a vacuum mold for $30 \mathrm{~min}$ obtaining fusion-bonded joints.

The presence of a sizing agent on GF surface influences both the degree of conversion of $\mathrm{CBT}^{81}$ and the GF adhesion, leading to very good adhesion strength with aminosilane-based sizes and epoxy resin film former. ${ }^{88}$ In the case of unidirectional composites laminates prepared by vacuum consolidation, ${ }^{89}$ a $\mathrm{pCBT} / \mathrm{GF}$ composite polymerized at $230{ }^{\circ} \mathrm{C}$ was compared with PBT/GF composites made from pre-preg tapes or co-mingled yarns. SEM and optical microscopies revealed a good fiber wetting in the PCBT/GF sample; nevertheless, some voids were observed within the polymer matrix. To improve the toughness of pCBT/GF composites, Baets et al. ${ }^{90}$ used polycaprolactone (PCL) and developed a non-isothermal production process.

Continuous fiber-reinforced PCBT composites containing $\mathrm{CF}^{83,91}$ or carbon fabric ${ }^{26,85,86}$ have been investigated by many researchers. Different experimental conditions for composite manufacturing processes based on melt blending, compression molding and vacuum infusion were proposed. A high-speed process for obtaining laminates involving compression molding at $250{ }^{\circ} \mathrm{C}, 1 \mathrm{MPa}$ for 2 min was successfully developed. ${ }^{85,92}$ Moreover, several toughening methods, such as annealing, ${ }^{92}$ or addition of binders (epoxies, acrylics, or random terpolymers of ethylene, methyl acrylate and glycidyl methacrylate) ${ }^{26}$ or chain extenders (bifunctional epoxy 
modifiers, isocyanates), ${ }^{26,93}$ were applied to improve their mechanical and fracture properties. The best annealing conditions for enhancing the mechanical properties and thermal stability of pCBT due to the improvement in crystallinity ${ }^{92}$ resulted $200{ }^{\circ} \mathrm{C}$ for $120 \mathrm{~min}$. Carbon fabric-pCBT laminates containing acrylicbased binders showed the best performance in terms of laminate homogeneity and magnitude of the final fracture toughness. ${ }^{94}$ To improve interfacial bonding between CF fabrics and the pCBT matrix, Lee et al..$^{95}$ treated CF fabrics with specifically designed microwave plasma equipment. Composites of pCBT with as-received and plasma-treated CF were obtained by polymerizing CBT with the high-speed process at $250{ }^{\circ} \mathrm{C}$ for 2 min. The increase in the surface roughness with micro-cavities and striations induced by the surface treatment on $\mathrm{CF}$ resulted in a composite characterized by superior tensile strength.

More recently, in-situ ED-ROP of CBT was reported as a successful method for the preparation of hybrid pCBT composites containing both carbon fabrics and nanofillers (see Paragraph 3.3), such as nanosilica, ${ }^{86}$ carbon nanotubes (CNT) ${ }^{83}$ and graphene nanoplatelets (GNP). ${ }^{83}$ Hybrid composites containing nanosilica (0.5-2 wt\%) were prepared by Liang et al. ${ }^{86}$ from woven carbon fiber/CBT pre-pregs. Carbon fabric cloths were wetted with molten CBT and an alcoholic nanosilica suspension containing also a tin-based catalyst was spread over them. After having removed the solvent, the layers were stacked and molded at $230{ }^{\circ} \mathrm{C}$ for $1 \mathrm{~h}$. The so-obtained hybrid composites displayed increased mechanical performances with respect to the sample without nanosilica. Jang and coworkers ${ }^{83}$ fabricated repairable and conductive hybrid composites based on pCBT and CNT or GNP and characterized by improved electrical and thermal conductivities. CBT powder and carbonaceous nanofillers were mixed to the target content (from 1 to $20 \mathrm{wt} \%$ ) in a planetary centrifugal mixer. The obtained mixture was sprayed onto a metallic mold and a carbon fabric was then laminated onto it. This process was repeated several times to obtain the intended specimen thickness. The sample was then compression molded at $250{ }^{\circ} \mathrm{C}, 15 \mathrm{MPa}$ for $2 \mathrm{~min}$. Irrespective of the nanofiller type, the electrical conductivity of the three-component (pCBT matrix, carbon fabric and carbonaceous nanofiller) composites was superior to those of the two-component counterparts, consisting of polymer matrix and either CNT or GNP nanofiller. The three-component composites with GNP, compared with the CNT-based analogues, exhibited improved thermal conductivity with the best result for the sample filled with 20 wt\% GNP. Tensile strength of composites decreased for nanofiller loadings higher than 5 wt\%; however, this can be overcome by incorporating nanofillers only in the outermost layers. Based on applicability tests for electrostatic powder painting and heat dissipation, these composites have potential in automotive part applications, such as outer panels and engine blocks, where electrostatic powder coating and/or heat dissipation are required.

Much less work has been devoted in the literature to composite materials prepared using macrocycles other than CBT. ${ }^{54}$ More dated research regarded composites containing carbon fibers or nanofibers were obtained by starting from cyclic polycarbonate oligomers, ${ }^{11,96,97}$ while more recent works reported the use of cyclic (arylene disulfide) oligomers ${ }^{98}$ and aryl ether ketone macrocycles. ${ }^{99}$ Song et al. ${ }^{98}$ prepared composites of poly(arylene disulfide) (PADS) reinforced with short CF by in-situ ED-ROP of cyclo(4,4'-oxybis(benzene)disulfide) (COBDS, see Chart 1) upon melt molding carried out in air at $200{ }^{\circ} \mathrm{C}$ for $30 \mathrm{~min}$ without catalyst. Compared to neat PADS, PADS/short CF composites are characterized by improved flexural modulus and strength due to the good adhesion between the in-situ formed PADS matrix and CF reinforcement. Misasi et al. ${ }^{99}$ very recently applied this ED-ROP approach to the development of PAEK-based composites containing CF. Cesium fluoride was used as a catalyst and ED-ROP of the corresponding MCOs was carried out in nitrogen atmosphere for 30 min at temperatures ranging from 280 and $300{ }^{\circ} \mathrm{C}$ while applying pressures from 500 to $1000 \mathrm{kPa}$. A lay-up process was adopted for composite preparation: over a layer of Kapton ${ }^{\mathrm{TM}}$ release film was placed a first ply of CF followed by the application of an MCO/CsF solution. This procedure was repeated up to a total of 10 plies and a Kapton ${ }^{\mathrm{TM}}$ release layer was finally placed on the top of the laminate. An excellent consolidation of the laminate was 
obtained at $300^{\circ} \mathrm{C}$. The removal of the dimer from MCOs prior ED-ROP was demonstrated to reduce the reaction temperature at $290^{\circ} \mathrm{C}$ and have a beneficial impact on dynamic mechanical properties.

3.2.2. Eco-composites with natural fibers. Due to growing global environmental and social concerns, the search for new eco-sustainable materials is nowadays highly encouraged. Thus, the combination of plant fibers (e.g., bamboo, coir, flax, hemp, jute, sisal, etc.) with biodegradable polymers provides an opportunity for the development of fully compostable/biodegradable composite materials characterized by lightness, low environmental impact, recyclability, and favorable cost/performance ratio. ${ }^{44-46,100-102}$ Indeed, the use of lowcost natural fibers, ${ }^{103}$ possibly arising from manufacturing by-products or agro-food wastes, is of great interest for the growth of the circular economy. The attainment of eco-composites with good mechanical properties requires however improvement in the compatibility between ligno-cellulosic fibers, characterized by a pronounced hydrophilic character, and polymer matrices, which are typically apolar or only weakly polar. Moreover, processing of classical polycondensates may require relatively elevated temperatures, so the processing temperature may be a crucial parameter in infusion processes, especially when natural fiber reinforcements are envisaged. In fact, high processing temperatures could cause partial thermal degradation of natural fibers (e.g., flax, hemp), which results detrimental for properties of ensuing composites, especially during extended processing times at temperatures higher than $200{ }^{\circ} \mathrm{C} .{ }^{104,105}$

The use of natural materials and fabrication of composites therefrom, and, particularly, the development of natural fiber-reinforced TPCs (also labelled NFRCs) appear therefore very promising, although various issues related both to materials and processing still need to be addressed to achieve manufactured items with longterm stability and performance. ${ }^{106}$ Taking into account what said above and notwithstanding the advantages that ED-ROP of low-melting MCOs could offer in preparing NFRCs, very few examples are reported in the literature on this topic. ${ }^{107-109}$ Romão et al. ${ }^{107,108}$ produced pCBT-based composites with 32 vol\% of flax fiber fabric by TP-RTM technique. Commercial CBT were infused in a closed mold containing the dry fiber pre-form. The composite products, demolded after macrocycles polymerization carried out at $190{ }^{\circ} \mathrm{C}$ for 30 min, were however weak and brittle, with low interfacial adhesion. The authors ascribed the brittleness to the high crystallinity of formed pCBT resin, as determined by DSC analysis, while the poor fiber-polymer adhesion was attributed to the absence of a suitable fiber compatibilization treatment. In a recent work Conzatti et al. ${ }^{109}$ achieved "fully green" eco-composites, that is constituted of a biodegradable polyester matrix, namely poly(1,4butylene adipate-co-terephthalate) (PBAT), reinforced with raw hemp fibers from agricultural wastes. MCOs of PBAT (CBAT, see Chart 1) were, for the first time, successfully prepared in quantitative yields by CDP reaction in mild conditions and exploited as a suitable coupling agent between the PBAT matrix and hemp fibers. The reconversion of the macrocycles into linear oligomeric/polymeric chains was successfully accomplished by EDROP, simply heating the macrocycles as obtained from CDP (without any further addition of catalyst) and preadsorbed onto long hemp fibers previously mildly mercerized and combed. The so-obtained hemp fibers with pCBAT chains grafted onto their surface were then incorporated into a PBAT matrix by compression molding. The achieved PBAT-based eco-composites reinforced with 40 wt\% of pCBAT-grafted hemp fibers showed enhanced fiber/matrix adhesion and, in turn, greatly improved mechanical and dynamic-mechanical properties, when compared not only to the neat PBAT but also to composites with the same amount of pristine or mercerized-fibers.

3.2.3. Composites with micrometric particulate fillers. Although the addition of fillers in the plastics industry has been exploited for several decades, mainly for their potential in improving the mechanical properties but also for cost reduction, polymer composites containing micrometric particulate fillers still receive great interest.

A couple of examples of exploitation of ED-ROP of macrocycles for fabrication of polymer composites with traditional particulate are given here. Deshmukh and co-workers ${ }^{110}$ applied ED-ROP of CBT in the presence of 
mica or talc microparticles. pCBT-based composites containing up to $30 \mathrm{wt} \%$ filler were prepared by melt blending in a single screw extruder. Good interfacial filler-matrix interaction, because of hydrogen bonding, justified mechanical, thermal, and structural properties of the resulting materials. The best properties obtained for the composites containing mica could be attributed to the higher aspect ratio of mica particles as compared to talc. In another work, ${ }^{111}$ to improve conductivity and decrease viscosity and electrical resistivity, composites containing both carbon black (CB) and graphite were prepared carrying out ED-ROP of CBT by melt blending in an internal mixer. SEM analysis suggested that CB fills voids formed by graphite, forming a compact conductive network, as confirmed by electrical resistivity measurements.

Particulate inorganic fillers are also interesting for specific applications, such as those related to the biomedical field. In tissue engineering, bioactive ceramics/polymer composites can combine the advantages of both components to better mimic hard and soft tissues in their physiological environment. ${ }^{112}$ Aliphatic polyesters are one the most investigated polymer class for biomedical applications thanks to their mechanical properties, biodegradability/bioresorbability and bioactivity which depend on their structures and functional groups. Constructs based on aliphatic polyesters such as $\mathrm{PCL},{ }^{113}$ and $\mathrm{PBS},{ }^{114}$ just to mention the most investigated, serve a temporary mechanical and/or therapeutic function until they gradually degrade (i.e., they are bioresorbed) and are replaced by the growing tissues upon prolonged implantation. On the other hand, aromatic polyesters possess superior mechanical properties, but also, they are more bioinert (thus not bioresorbable in the due time) in physiological environments.

A ceramic filler largely used for mimicking the natural bone system is hydroxyapatite (HAp); while calcium silicate was demonstrated to have a high ability to induce upon soaking in liquid simulating body fluids the fast formation of a HAp layer which can favor bonding with living bone. ${ }^{115}$ Composites containing HAp $^{116,117}$ or calcium silicate ${ }^{113}$ are obtained by ED-ROP of cyclic oligo(ethylene terephthalate) or cyclic oligo(ethylene adipate)-co-oligo(ethylene terephthalate) in the presence of di- $n$-butyltin oxide catalyst. MCOs were previously obtained from CDP of the corresponding polyesters. Different reaction temperatures were tested; $250^{\circ} \mathrm{C}$ proved to be the most effective when performing ED-ROP within microporous HAp templates. ${ }^{117}$ The bioactivity of the resulting composite constructs was verified by soaking them in simulated body fluids.

\subsection{Nanocomposites}

Polymer nanocomposites, that is composites in which the reinforcement/filler embedded in the polymer matrix has at least one dimension in the nanometer range, have received a great deal of attention in the past three decades. ${ }^{33,34,47,48}$ Indeed, provided the nanofiller is homogeneously distributed and dispersed at the nanoscale level within the polymer matrix, the resulting nanocomposite is expected to have strikingly improved properties, mainly mechanical, but also thermal, barrier and others, compared to the pure polymer, even at very low loads (below 1 wt\%). However, despite the high interest aroused, a major challenge in the development of highperformance nanocomposites is the effective control of the nanofiller dispersion.

Polymer-based nanocomposites can be classified in variable ways, depending, e.g., on the type of polymer matrix (thermosets, thermoplastics, elastomers, with their subcategories), nature of the nanofiller (ceramic, metallic, carbonaceous), dimensionality of the dispersed nanofiller. ${ }^{118}$ On this point, it must be said that browsing the web one encounters classifications which can be misleading, often use different languages and are even discordant with each other (this depends very much on the applications and philosophy for which they are adopted). ${ }^{119}$ Here, the reviewed works are classified into four categories on the base of nanofiller dimensionality: three-dimensional (3D), that is particles having three nanometric dimensions such as nanosilica, $\mathrm{CB}$; two-dimensional (2D), that is sheets, platelets, layers having one dimension in the nanometer range, such as layered silicates, layered double hydroxides, graphene and graphene oxide nanoplatelets; one-dimensional 
(1D), that is tubes, rods, wires, fibers having two dimensions in the nanoscale, such as carbon nanofibers, carbon nanotubes, cellulose whiskers, gold nanowires; zero-dimensional (OD), that is ultra-small size nanostructures with spherical or quasi-spherical geometry, such as fullerenes, quantum dots, polyhedral oligomeric silsesquioxanes, gold nanoparticles.

The low viscosity of the molten cyclic oligomers has been exploited to achieve polymer nanocomposites with improved properties, indeed nanofiller distribution/dispersion ${ }^{120}$ can be enhanced by reducing the matrix viscosity. In the case of layered nanofillers, ${ }^{121,122}$ intercalation/exfoliation is favored by MCO intercalation in between the nanofiller layers with further interlayer expansion upon in-situ ED-ROP. Also for nanocomposites, CBT oligomers have been the most investigated ones, even if cyclic oligomers of PET, PHT, other polyesters, polycarbonates, PADS have been considered.

3.3.1. 3D nanoparticles. The preparation of nanocomposites by in-situ ED-ROP of cyclic oligomers has been investigated for 3D nanoparticles, such as nanosilica and CB, constituted of ultra-small individual particles which however form nanoclusters with all three dimensions below $100 \mathrm{~nm}$. In particular, several works dealt with the pair pCBT/silica nanoparticles. ${ }^{123,124}$ These studies were aimed at investigating the effect of silica nanoparticles and catalyst amount on the in-situ CBT polymerization process and, in turn, on thermal and mechanical properties of the ensuing PCBT-based nanocomposites. These were obtained in two steps: firstly, silica nanoparticles were mixed by high-speed stirring with molten CBT; ED-ROP was then conducted in the presence of a tin-based catalyst at temperature $\geq 200{ }^{\circ} \mathrm{C}$ for $1 \mathrm{~h}$. Morphological analysis indicated a homogeneous distribution of sub-micrometric agglomerates and individual nanoparticles in the formed pCBT matrix. As observed for neat CBT treated in analogous conditions, ${ }^{11,125,126}$ the viscosity stayed almost constant for a certain time and then steeply arose. This induction time was greatly prolonged by the incorporation of silica nanoparticles: ${ }^{124}$ the same viscosity (ca. $10000 \mathrm{~Pa}$ s) was reached in $200 \mathrm{~s}$ for neat CBT and in $1400 \mathrm{~s}$ for CBT containing nanosilica. An amount of $0.6 \mathrm{wt} \%$ catalyst gave nanocomposites with improved mechanical and thermal properties, without affecting the crystallinity degree of the PCBT matrix. ${ }^{124}$ The flexural properties of the nanocomposites, including modulus, yield strength and failure strain, were significantly improved by incorporation of silica nanoparticles. ${ }^{123}$

3.3.2. 2D nanoparticles. Phyllosilicates or clays, the best-known representative of which is montmorillonite (MMT), as well as graphene $(G)$ and graphene oxide $(G O)$ are the 2D nanoparticles mostly investigated for the exploitation of ED-ROP reaction of strainless MCOs in the preparation of polyester-based nanocomposites. Such nanofillers are characterized by stacked layers with nanometric thickness, high surface area, and large lateral length-to-thickness ratio. $\mathrm{MMT}^{33,47}$ is a 2:1 layered silicate with a crystalline structure made of two layers of silicon oxide fused to a sandwiched layer of aluminum hydroxide. Isomorphic substitution of higher valence cations by lower valence ones (e.g., $\mathrm{Al}^{3+}$ by $\mathrm{Mg}^{2+}$ ) renders the layers negatively charged. This negative surface charge is counterbalanced by alkali cations located in-between the clay galleries. Graphene ${ }^{127,128}$ is made of single-atom-thick carbon nanosheets with a planar honeycomb lattice, constituting a research hotspot in various fields since its discovery. Compared with MMT, G possesses extremely low density and superior mechanical, electrical, and thermal properties.

Despite their promising properties, 2D nanosheets tend to stack and agglomerate because of their high surface energy. In the case of MMT, to achieve its uniform dispersion within the polymer matrix, typically hydrophobic, the alkali metal cations present in-between the galleries are generally ion exchanged with more hydrophobic organic cations, the latter usually being tetrasubstituted ammonium cations bearing long alkyl chains. $^{33,47}$ In such a way, the silicate galleries not only become more hydrophobic, but at the same time the sheets of silicate move further apart so facilitating the intercalation of the polymer chains. On the other hand, the production of high-quality monolayer graphene sheets is still limited at a relatively small scale. Graphitic 
nanofillers, ${ }^{129}$ including $\mathrm{G}$ (low amounts), graphite nanoplatelets (GNP), GO, reduced GO (RGO), few-layer graphene (FLG) and multi-layer graphene (MLG) can be produced in sufficient amounts for polymer nanocomposite production by oxidation and salification of graphite followed by chemical or thermal reduction, electrochemical exfoliation of graphite, and liquid phase exfoliation of graphite. Moreover, $G$ exfoliation remains a major challenge due to the strong $\pi-\pi$ stacking of the $\pi$ orbitals of carbon atoms on adjacent sheets. ${ }^{130,131}$

In the "ED-ROP world", the most popular strategy adopted for preparing MMT-based nanocomposites exploits the low viscosity of molten or dissolved CET or CBT cycles to obtain MCO-intercalated organoclays. MCOs, organo-modified clay and a catalyst, most frequently a tin-based catalyst, are carefully mixed;26,120,132-137 the subsequent ED-ROP undergoes by simply heating causing an increase in the interlayer distance along with the disintegration of the layered clay structure, as shown in Figure 1.
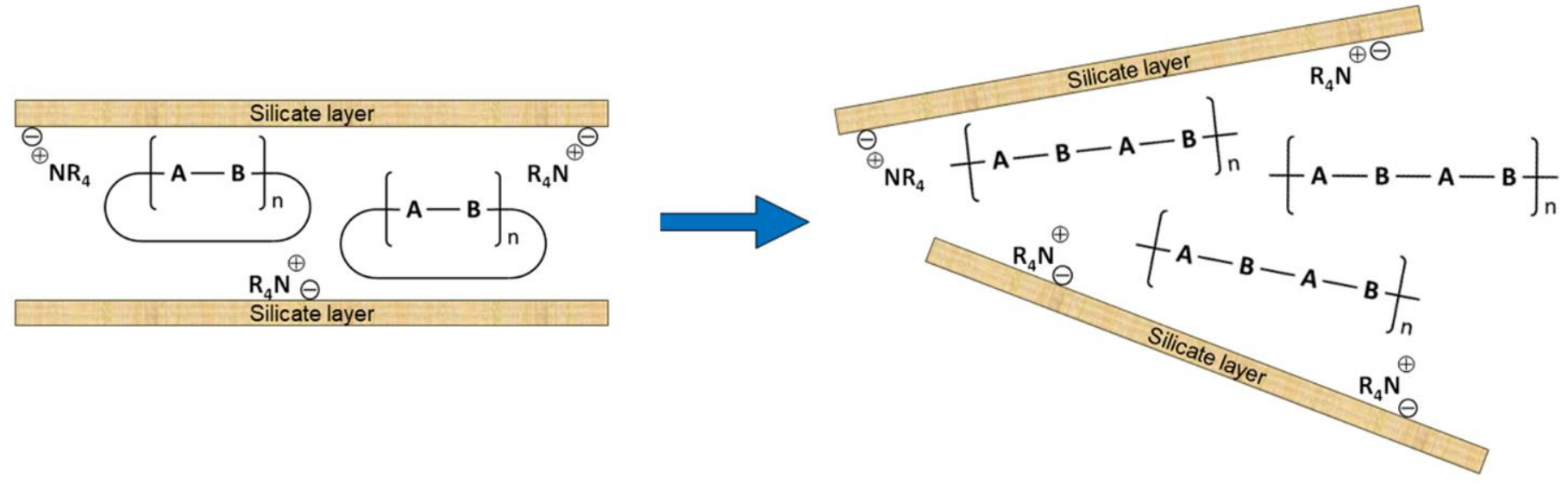

Figure 1. Schematic depiction of ED-ROP of MCOs intercalated in-between clay layers.

It must be said that even when the cyclic oligomers are successfully intercalated in-between the organoclay layers, complete clay exfoliation is difficult to achieve in the final nanocomposites: flocculated-intercalated, intercalated or partially exfoliated structures are commonly observed. Moreover, the organoclay seems to limit both the macrocycles conversion and molecular weight of the resulting polymer ( $p C E T, p C B T, p C B P A C)^{120,133,138}$ while shifting the ED-ROP towards higher temperatures. ${ }^{139} \mathrm{Hong}$ and Lee found the best results in terms of MMT dispersion and final properties if ED-ROP of intercalated CBT is carried out at $240{ }^{\circ} \mathrm{C}$ in the presence of a Tibased catalyst. ${ }^{136}$ By performing ED-ROP of CET with the same catalyst, satisfactory molecular weights $\left(M_{\mathrm{n}}=\right.$ $11000 \mathrm{~g} / \mathrm{mol}$ ) were obtained only at reaction temperatures near the melting point of ET-cyclic trimer or tetramer (ca. $310{ }^{\circ} \mathrm{C}$ ). ${ }^{120} \mathrm{CHT}$ efficiently polymerized in the presence of organo-modified MMT and tin octoate by performing ED-ROP at $160{ }^{\circ} \mathrm{C}$ for $24 \mathrm{~h} .{ }^{139} \mathrm{~A}$ bisphenol-A polycarbonate matrix with $M_{\mathrm{w}}$ around $40000 \mathrm{~g} / \mathrm{mol}$ was obtained by carrying out ED-ROP $\left(240{ }^{\circ} \mathrm{C}, 10 \mathrm{~min}\right)$ of a mixture of MMT/CBPAC/initiator $\left(\mathrm{Bu}_{4} \mathrm{NBPh}_{4}\right)$ previously annealed by applying shear in an internal mixer $\left(180^{\circ} \mathrm{C}, 1 \mathrm{~h}\right) . .^{138}$

The reorganization/flocculation of silicate layers ${ }^{132,139,141}$ could be caused by the low viscosity of the molten CBT and by the thermal instability of the ammonium-based compensating cations bearing long alkyl chains usually employed. Indeed, even under non-oxidative conditions, these begin to decompose at temperatures near $180^{\circ} \mathrm{C}^{142}$ which are lower than those needed to achieve ED-ROP of the intercalated CBT. To overcome this drawback, Conzatti et al. ${ }^{137}$ anchored in-between the clay galleries a highly thermally stable alkylimidazolium salt bearing a tin-based moiety which proved highly effective in the ED-ROP reaction $\left(190{ }^{\circ} \mathrm{C}, 30 \mathrm{~min}\right)$ of 
intercalated CBT yielding a polymer fraction higher than $95 \%$ and molecular weights $\left(M_{\mathrm{w}}\right)$ around $50000 \mathrm{~g} / \mathrm{mol}$. Moreover, by applying mechanical stirring during ED-ROP, practically quantitative yields and molecular weights were obtained ( $\left.M_{\mathrm{w}} 80000 \mathrm{~g} / \mathrm{mol}, \mathrm{PDI} 2\right)$ comparable to those $\left(M_{\mathrm{w}} 85500 \mathrm{~g} / \mathrm{mol}, \mathrm{PDI} 1.8\right)$ of the commercial PBT used for CBT preparation by CDP. A mix of intercalated and exfoliated silicate nanolayers were observed in the ensuing PBT-based nanocomposites with consequent improvements of their thermo-oxidative stability.

Along with MMT, other layered fillers were explored for the preparation of nanocomposites by in-situ ED-ROP. Layered double hydroxides (LDH) are anion-exchange clays constituted of layers formed by octahedral units with shared edges; the best known and naturally occurring LDH is hydrotalcite. ${ }^{143}$ For instance, Berti et al. ${ }^{144}$ modified LDH by intercalating with various intercalating anions to favor its exfoliation, also using different starting materials and experimental conditions. Nanocomposites were also prepared by ED-ROP of CBT successfully performed at $190{ }^{\circ} \mathrm{C}$ in the presence of a cyclic tin oxide initiator with LDH organo-modified using sodium dodecyl sulfate. This modifier led to an initial high space gallery, thus favoring the diffusion of the large cyclic oligomers. The ensuing LDH-based nanocomposites showed better dynamical mechanical properties with respect to those of a sample containing an alkyl ammonium modified MMT.

Vermiculite (VMT) is a mica-type silicate which belongs to the general family of 2:1 layered silicates. The approach followed by Du et al. ${ }^{145}$ for the in-situ preparation of PADS-based nanocomposites is similar to that used for polyester/MMT nanocomposites. COBDS (see Chart 1) was mechanically mixed with VMT modified with octadecylammonium chloride. Intercalation of organo-vermiculite was obtained by statical annealing at $140{ }^{\circ} \mathrm{C}$, while ED-ROP of COBDS was spontaneously carried out at $200{ }^{\circ} \mathrm{C}$ by compression molding. The obtained high degree of dispersion of the VMT layers led to enhanced dynamic-mechanical properties and higher glass transition temperature compared with the pure PADS.

The low melt viscosity of MCOs may also favor graphene exfoliation. In-situ ED-ROP was indeed exploited for the preparation of pCBT-based nanocomposites containing graphitic nanofillers, ${ }^{26,129,146-148}$ which are blended with CBT both in a solvent (THF, acetone) or in the molten state. ED-ROP was carried in the presence of tin-based initiators at temperatures higher than $200{ }^{\circ} \mathrm{C}$ with or without mechanical stirring, in a batch mixer or a co-rotating twin-screw mini-extruder. Also, a solvent-free processing method involving powder mixing and subsequent in-situ polymerization during compression molding at $250{ }^{\circ} \mathrm{C}$ was developed. Overall results indicate that graphene nanoplatelets are difficult to exfoliate and disperse homogeneously in the pCBT matrix. More importantly, it seems that these nanofillers interfere with the ED-ROP of CBT, obtaining final pCBT with rather low molecular weights and then brittle nanocomposites. Nevertheless, thermal stability and heat conductivity are improved, and the nanocomposites are electrically conductive. Chemical functionalization of graphene, via oxidation followed by reduction, could be of crucial importance in improving the nanofiller dispersion because it should effectively prevent restacking of the exfoliated graphene sheets due to reduced $\pi-\pi$ interactions and it could be employed for covalent bonding with polymer chains. Indeed, GO platelets are highly hydrophilic due to the presence of epoxide, diol, ketone, hydroxyl, and carboxyl functional groups on the basal plane and additional carbonyl and carboxyl groups at their edges. The successive chemical or thermal reduction of GO leads respectively to RGO or TRGO platelets retaining some of the oxygenated functional groups originally present on the GO platelets. ${ }^{149}$ Nevertheless, reduced GOs have been used in several papers ${ }^{129,146}$ focused on ED-ROP of CBT but no marked improvements were recorded, especially in terms of rate and degree of polymerization.

By using fillers with different surface polarity (graphite, CNT, TRGO or $\mathrm{SiO}_{2}$ ) and performing CBT ED-ROP in static conditions, Chen et al. ${ }^{146}$ showed the important role of surface functional groups on nanofillers in affecting ED-ROP of macrocycles. Samples with graphite and CNT had similar polymerization rate as pure CBT; those with TRGO greatly extended the reaction time, and those with silica had the lowest polymerization rate. The presence 
on the nanofiller surface of epoxy and/or hydroxyl functionalities inhibits the polymerization of CBT. Moreover, several lines of evidence proved the grafting of PCBT polymer chains onto TRGO nanoparticles and this resulted in a very fine dispersion with a homogeneous distribution of single-layer or few-layers graphene nanosheets within PBT matrix. A mechanism for CBT polymerization starting from TRGO was also proposed.

ED-ROP polymerization of CBT in the presence of different types of graphene-related materials (GNP, RGO, overoxidized-intercalated graphite) was explored by Colonna et al. during extrusion. ${ }^{148}$ As already observed, the molecular weight of the obtained PCBT is strongly reduced by the presence of the nanofiller. Moreover, poor dispersion and distribution of nanofillers were obtained due to the extremely low viscosity of CBT during compounding that did not allow the application of sufficiently high shears. Both thermal and electrical conductivity of the resulting materials were strongly affected by the quality of graphene-based nanofillers.

The in-situ ED-ROP of COBDS was explored by Du et al. ${ }^{150}$ for the preparation of poly(arylene disulfide)/graphite nanosheet composites. The polymerization of COBDS intercalated into graphite nanosheets was carried out by compression molding at $200{ }^{\circ} \mathrm{C}$ for $30 \mathrm{~min}$ without the use of a catalyst. Conductive nanocomposites containing $5 \mathrm{wt} \%$ graphite were obtained.

3.3.3. 1D nanoparticles. The already mentioned carbon nanotubes (CNT) are nanofillers with exceptionally high aspect ratios constituted by graphene sheets rolled up into cylindrical form and capped with half a shape of fullerene structure. ${ }^{151}$ Depending on the number of graphene sheets, they are classified as: (i) single-walled carbon nanotubes (SWCNT), essentially consisting of a single graphene sheet rolled into a cylinder, or (ii) multiwalled carbon nanotubes (MWCNT), made of two or more coaxial graphene cylindrical layers with an interspacing of about $0.34 \mathrm{~nm}$. Their lightness coupled with remarkable mechanical, electrical, and thermal properties ${ }^{152}$ make them quite appealing as reinforcing agents in polymer nanocomposites. As prepared CNT tend to form bundles hold together by van der Waals forces forming entangled structures hard to break up, so that the achievement of polymer-based nanocomposites with individually dispersed nanotubes is a great challenge, especially by using traditional processing methods as melt mixing or RTM.

Despite the high interest in polymer/CNT nanocomposites for electrical and conductive applications, only a few papers dealing with the ED-ROP of macrocycles, mainly CBT, are present in the literature. ${ }^{26}$ In most of them, as-obtained or surface-treated MWCNT were used, in some cases CNT mats were also explored to impart/improve conductivity. Different methods to disperse MWCNT in CBT were investigated: solvent blending, solvent-free powder mixing in a planetary centrifugal mixer, solid-phase high-energy ball milling and melt blending in a simple rotational mixer. The subsequent ED-ROP reaction was mostly performed by heating under compression molding, although vacuum-assisted RTM was also explored. As observed for graphene- and silicate-based nanofillers, the molecular weight of PCBT decreased when MWCNT were present in the blends. Optimal properties were found with very low amounts of MWCNT; moreover, the presence on MWCNT surface of functionalities arising from treatments with acid, hydrogen peroxide, and heat affected the nanofiller dispersion, which was found to be the principal factor governing the electrical percolation behavior of the resulting nanocomposites. The electrical percolation threshold decreased by passing from pristine or acidtreated MWCNT (about 3 wt\% load) up to those treated with hydrogen peroxide or heat (<1 wt\%).

To improve the compatibility between PBT matrix and MWCNT, Wu and co-workers ${ }^{153,154}$ applied a "grafting from" approach. They synthesized a novel MWCNT-supported cyclic initiator from dibutyl tin(IV) oxide and hydroxyl- ${ }^{153}$ or carboxyl-functionalized ${ }^{154}$ MWCNT. The Sn-O bonds obtained on the nanofiller surface provided the initiating sites for the in-situ ED-ROP of CBT. Amounts higher than 50 wt\% of pCBT long-chain macromolecules were thus grafted onto the MWCNT surface, effectively providing a compatibilizer for PBTbased nanocomposites. Results indicated a homogeneous dispersion in the PBT matrix when MWCNT content is lower than $0.75 \mathrm{wt} \%$ and a nucleating effect exerted by the nanofiller on PBT crystallization. ${ }^{153}$ 
For nanocomposites with 1D nanofillers, the only example exploiting ED-ROP with a polyester matrix different from PBT is from Gonzalez-Vidal et al. ${ }^{155}$ They prepared PHT-based nanocomposites containing different amounts of pristine or OH-functionalized MWCNT by in-situ ED-ROP of CHT cycles or by melt blending $\mathrm{PHT} / \mathrm{CNT}$ mixtures. CHT with 2-7 repeat units were obtained by CDP of PHT and solvent blended with CNT and $\mathrm{Sb}_{2} \mathrm{O}_{3}$ as a catalyst. The ED-ROP reaction was carried out in static conditions under nitrogen at $200{ }^{\circ} \mathrm{C}$ for $30 \mathrm{~min}$. The preparation by melt blending was performed in a twin-screw mini-extruder. Temperature was set at $150{ }^{\circ} \mathrm{C}$ and the mixture was recirculated for $3 \mathrm{~min}$. Reinforcement of PHT with MWCNT afforded thermally stable materials with improved mechanical properties and enhanced crystallizability (nanotubes acted as nucleating agent), effects that were more efficiently attained when nanocomposites were prepared by ED-ROP and functionalized CNT were used.

3.3.4. OD nanoparticles. Polyhedral oligomeric silsesquioxanes (POSS) have attracted a great deal of attention in recent years as reinforcing agents in polymer nanocomposites thanks to their capability of suitably interacting with polymer matrices through their organic functionalities. ${ }^{156}$ Cage-structured POSS constitute a unique family of molecular materials with zero-dimensionality (size about 1-3 nm), composed of an inorganic silica-like cage $\left(\mathrm{Si}_{8} \mathrm{O}_{12}\right)$ surrounded by eight covalently bonded organic (polar or non-polar) vertex groups. These are responsible for the functionality, solubility, polarity, and reactivity of the $\mathrm{R}_{8} \mathrm{Si}_{8} \mathrm{O}_{12}$ molecules and can be easily tailored. The interactions and/or reactions of the functional groups at the interface with the polymer matrix favor compatibility, and may result in the nanometric dispersion of POSS. Although POSS are versatile nano-building blocks, very few papers investigate POSS for in-situ ED-ROP in polymer-based nanocomposites. ${ }^{141,157,158}$

Wu et al. ${ }^{157}$ synthesized a POSS-Sn initiator by reacting trisilanolisooctyl POSS with butyltin trichloride initiator for CBT. pCBT/POSS nanocomposites with up to $20 \mathrm{wt} \%$ of POSS content and characterized by slightly improved thermal properties were then obtained by in-situ ED-ROP during melt mixing. Molecular weight decreased by increasing the catalyst amount bonded to the POSS.

The use of POSS as compensating cation for MMTs appears as an interesting method to enlarge the MMT interlayer distance and create a supported initiator for ED-ROP polymerization. POSS-MMT organoclays were prepared by intercalating tailored POSS used as surfactants and then mixed with CBT and a tin-based catalyst. ${ }^{158}$ After having performed ED-ROP under slow stirring, the so-obtained masterbatch was melt compounded with virgin PBT to give nanocomposites with 3 wt\% clay. Intercalated/exfoliated morphology with a related increase in stiffness and strength was found, although the transesterification catalyst present in the masterbatch caused partial PBT depolymerization. Similarly, POSS-MMT-Sn supported catalyst was obtained by previous incorporation of an aminopropylisooctyl POSS followed by catalyst addition into the POSS-modified clay. ${ }^{158}$ This complex was used as initiator for the ED-ROP of CBT, thus achieving clay exfoliation even at 10 wt\% of clay loading. The $\mathrm{pCBT/POSS/clay} \mathrm{nanocomposite} \mathrm{was} \mathrm{further} \mathrm{used} \mathrm{as} \mathrm{a} \mathrm{masterbatch} \mathrm{to} \mathrm{dilute} \mathrm{in} \mathrm{conventional} \mathrm{PBT}$ obtaining increased stiffness and strength.

\section{Other Applications of ED-ROP}

The presence of MCOs in a polycondensate-based system, either during processing or in the finished material, can significantly modify its thermo-rheological behavior and/or ultimate properties. Some research studies exploiting the possibility offered by strainless macrocycles which in due time undergo polymerization via EDROP, thus acting from time to time as processing aid, compatibilizing agent, property modifier, or as combinations of the three, are presented in the following. Finally, the potentialities of the classical CDP/ED-ROP and enzymatic EC/ED pairs for materials recycling are briefly depicted. 


\subsection{Processing aid}

In previous paragraphs, it was shown that in-situ ED-ROP of macrocyclic oligomers, having greatly lowered melt viscosities compared to that of the parent polymer, enables more facile production of fiber-reinforced composite materials and fabrication of nanocomposites with better fiber-matrix adhesion and more evenly dispersed nanofillers, respectively.

Analogously, ED-ROP can be exploited to solve viscosity problems encountered during melt processing of high-molecular-weight, high-temperature-melting engineering polymers. In this case, the parent polymer can be processed in a blend with a minor amount of its homologous MCOs. Such a blend, having a substantially lower melt viscosity than the pure polymer, is much easier to process. During and/or after fabrication, the MCOs solubilized in the parent polymer undergo in-situ ED-ROP, to give exactly the same macromolecular material that contains only the normal equilibrium concentration of macrocycles.

This approach, exploiting MCOs as processing aid, was first demonstrated in an early joint work of Colquhoun, Hodge and Stanford. ${ }^{6}$ Blends of a high-performance PES derived from 4,4'-biphenol and 4,4'dichlorodiphenylsulfone (namely Radel- $\mathrm{R}^{\mathrm{TM}}$ ) with its homologous macrocyclic oligomers showed greatly lowered melt viscosities compared with the parent polymer, for instance a 10 wt\% of the MCOs lowered of about five-fold the polymer viscosity. The macrocycles present in the blend first acted as plasticizer drastically lowering melt viscosity and subsequently led to an enhancement of the polymer molecular weight by undergoing in-situ ED-ROP and aromatic ether interchange reaction. The required blend compositions were obtained easily in one step, by carrying out polycondensations of starting monomers at concentrations lower than those usually used for polymer synthesis.

In a successive work of Hodge and co-workers, ${ }^{49}$ a similar approach was employed to lower the melt viscosity of three commercial polyesters of uppermost importance. Blends of PET, PTT and PBT each with the corresponding CET, CTT and CBT cycles were prepared in various proportions by co-precipitation from a solvent. Melt viscometry analysis demonstrated that the blends were more easily melt-processed than the pure polymers, and the MCOs were converted in situ into high-molecular-weight polymers by ED-ROP reaction. It was shown that no catalyst is needed, the end groups present in the systems being sufficient. Suitable polymer/MCOs blends were also obtained directly by carrying out CDP reactions of the parent polymers at appropriate concentrations, thus saving solvent and time. The proportions of polymer and MCOs in the equilibrated mixtures as a function of initial polymer concentration for CDP were determined. For instance, in the PET system a mixture containing 20 wt\% of CET could be obtained by equilibrating the CDP reaction at a polymer concentration of $15 \% \mathrm{wt} / \mathrm{vol}$. The rheological behavior of this mixture was found to be substantially the same of that observed for the analogous blend obtained from co-precipitation of the parent polymer with previously prepared CET oligomers.

The potential of macrocyclic aromatic thioether-ketones (CTK) as transient processing aids for highperformance PEEK was demonstrated in a successive work of Manolakis and Colquhoun. ${ }^{159}$ As shown in Figure 2, blends of PEEK with CTK macrocycles showed initial melt viscosities reduced by more than an order of magnitude relative to the polymer itself, thus enabling more facile processing and fabrication. On raising the temperature of the melt, the macrocycles underwent spontaneous ED-ROP to give blends of PEEK with a highmolecular-weight poly(thioether ketone). On the basis of experimental evidence, it was envisaged that impregnation of, e.g., carbon fibers with macrocycle-plasticized PEEK could be carried out at $360-380{ }^{\circ} \mathrm{C}$, that is in a temperature range where spontaneous ring opening of aromatic CTK is slow, to fabricate a suitable prepreg, and ED-ROP could then be induced in the composite matrix by raising the temperature to $430-450{ }^{\circ} \mathrm{C}$ for a short time, as part of the final consolidation process to achieve the finished component. 

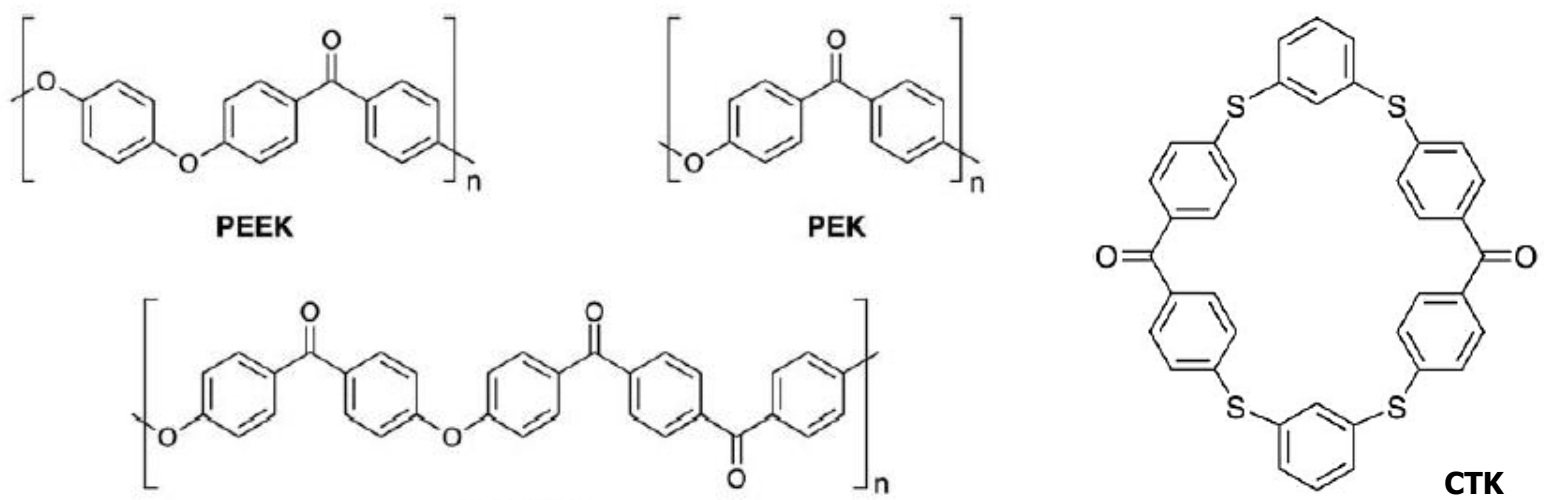

PEKEKK
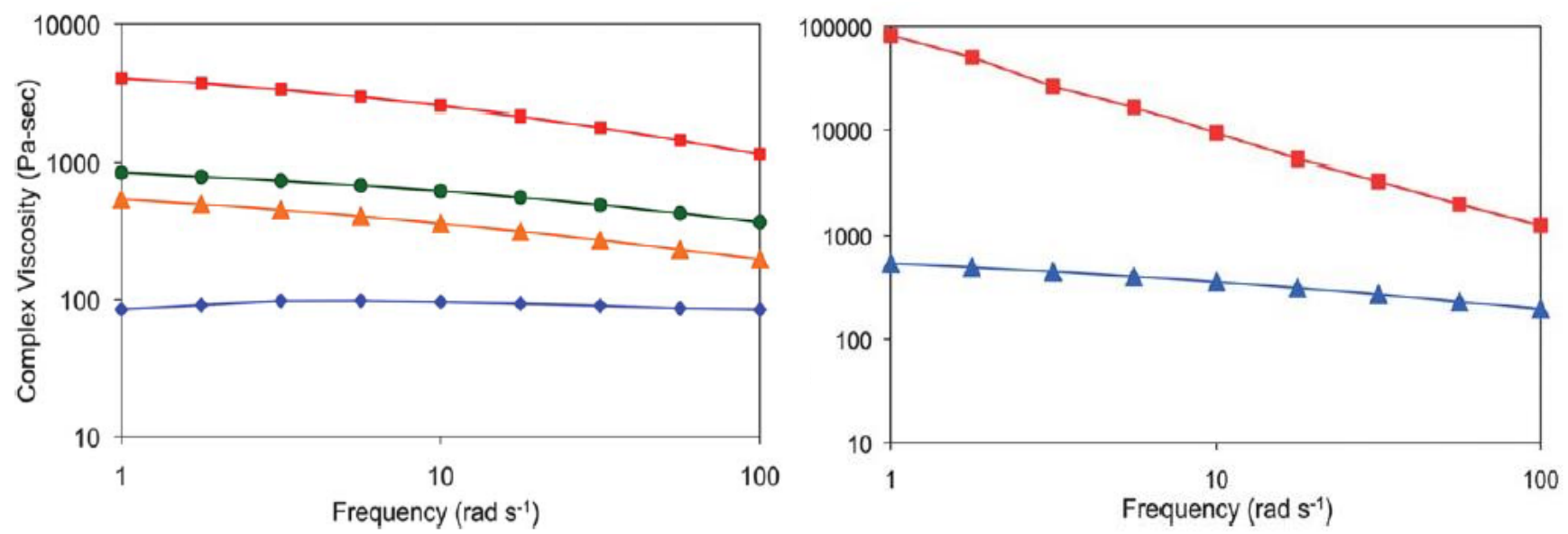

Figure 2. Industrially relevant PEEK, PEK and PEKEKK (top left) and CTK macrocycle (top right); melt viscosity at $350{ }^{\circ} \mathrm{C}$ as a function of macrocycle content: pure PEEK (red square) and PEEK/CTK blends 90/10 (green circle), 80/20 (orange triangle) and 60/40 (blue lozenge) wt/wt (bottom left) and for the 80/20 PEEK/CTK blend before (red square) and after (blue triangle) ring-opening polymerization (bottom right). Adapted from ref. 159.

\subsection{Compatibilization}

As discussed above, the fast polymerization kinetics and high reactivity of CBT are advantageous for the compatibilization of partially miscible polymer blends, while grafting of in-situ formed pCBT (or other polymerized cycles) on a nanofiller surface or on suitably functionalized (maleinized) polymers are useful techniques to improve interfacial adhesion in polymer-based multicomponent materials. In this respect, few other examples of compatibilization attained by exploiting ED-ROP of oligomeric macrocycles are here given.

In the field of conductive materials, the incorporation of conductive nano- and micro-sized fibers or fillers in a polymer-based matrix represents a very promising approach for the improvement of electrical conductivity. However, the formation within the polymer matrix of a double-percolated structure consisting of two types of percolation associated with the electrical continuity of the conductive particles in the filler-rich phase and with the continuity of this dispersed phase in the whole polymer blend/matrix is the requirement to attain high electrical conductivity. ${ }^{160}$ To this purpose, Abbasi and coworkers ${ }^{161}$ prepared a series of 36 ternary $\mathrm{PP} / \mathrm{CBT} / \mathrm{MWCNT}$ nanocomposites (up to $5 \mathrm{wt} \%$ final CNT loading) in a laboratory twin-screw extruder through a two-step procedure involving the dilution with appropriate amounts (up to $40 \mathrm{wt} \%$ ) of CBT of previously prepared CNT/PP nanocomposites in turn prepared from a PP/MWCNT masterbatch at 20 wt\% CNT by using 2 wt\% of maleic anhydride grafted polypropylene (PP-g-MA) coupling agent. This work was aimed at investigating 
the possibility of a more efficient wetting of the nanotubes by the MCOs that should result in a much better dispersion and distribution of the conductive nanofiller within the PP matrix with consequent improvement in terms of electrical conductivity. CBT oligomers were found beneficial in improving electrical conductivity of the resulting nanocomposites through the formation of a double percolation structure involving the percolation of nanotubes in a filler-rich phase and the continuity of this phase which both affected the electrical conductivity of the blended nanocomposites. On the other hand, the nanotubes also affected the morphology of the blends by increasing the viscosity of the filler-rich phase. As a consequence, smaller domains and more elongated dispersed phase were observed in the presence of nanotubes. The occurrence of a crystalline polymer structure improved the electrical conductivity and decreased the percolation threshold; moreover, smaller domains and more elongated dispersed phase (CNT) were observed in the presence of CBT.

The formation of a double continuous phase for the improvement of electrical performances was also the objective of Song et al. ${ }^{162}$ who prepared poly(vinylidene fluoride) (PVDF)/CBT/CB/graphite composites by melt blending. Their volume electrical resistivity linearly decreased as graphite content increased up to 4 wt $\%$ and their mechanical properties satisfied requirements for the preparation of bipolar plates.

Thermal conductivity of CNT-filled nanocomposites can be improved by the addition of a second nano-sized filler with large aspect ratio, such as expanded graphite (EG), for the effective formation of 3D thermally conductive networks into the polymer matrix. ${ }^{163}$ Following this approach, Kim and coworkers ${ }^{164}$ prepared by melt blending a PC/EG/CNT-pCBT composite starting from a CNT/pCBT masterbatch to enhance the dispersion of the carbonaceous filler. The masterbatch was prepared by powder mixing followed by compression molding to induce the in-situ ED-ROP of CBT cycles, as similarly done by the same research group for other nanocomposites. ${ }^{85,92}$ The thermal conductivity of the resulting composite containing 9.9 wt\% EG and 0.1 wt\% CNT was synergistically improved by $49 \%$ compared to that of the composite filled with 10 wt\% EG alone. This significant enhancement was due by an efficient CNT dispersion/distribution and the consequent formation of thermally conductive pathways.

ED-ROP of MCOs can help also to improve the adhesive bonding between polymer materials and metallic substrates. In a recent study Astigarraga et al. ${ }^{165}$ investigated the adhesive bonding of polymeric blends, based on PP matrix, CBT (neat or with 3 wt\% of tin-based catalyst added) and/or PP-g-MA to aluminum, with the aim of developing metal/polymer hybrid laminates for the automotive and aeronautic sectors. Different films (of final thickness $0.2 \mathrm{~mm}$ ) prepared from binary and ternary blends at various compositions were joined to the aluminum laminate by pressing. The adhesive bonding was tested under the standard UNE-EN 1465. For PP-g$\mathrm{MA} / \mathrm{PP}$ and CBT/PP binary blends, there is a PP-g-MA or CBT critical composition from which the shear strength values start to decline because of the formation of two regions whose interface fails with the application of stress. This effect is more evident in CBT/PP blends, due to the immiscibility of the two components. The combined presence of CBT and PP-g-MA resulted in higher shear resistance due to the enhanced polymer compatibility consequent to possible interactions (van der Waals forces and/or esterification and transesterification reactions) between CBT/pCBT and PP-g-MA. In addition, if the ED-ROP of CBT to pCBT takes place concurrently to the joining process, the shear resistance of the laminated increases by between 10 and $25 \%$. The adhesive bonding between layers improves in two ways: the lower viscosity of the developed blends makes easier substrate impregnation, and the active sites created during CBT ED-ROP can form chemical linkages.

\subsection{Properties modification}

The use of macrocycles, neat or in a minor amount, followed by their ED-ROP simply activated by temperature to give the same parent polymer has proven to be useful "per se" to lower melt viscosity in polymer processing, 
and hence to make easier fabrication of polymer-based composites and nanocomposites with improved quality and ultimate properties. On the other hand, addition of minor amounts of strainless cycles (and their subsequent ring-opening) in formulations in which the polymer matrix has a different nature from that of the parent polymer can allow for property-modification of multicomponent materials.

In automotive applications, epoxies are commonly employed because they ensure reliable fiber impregnation and create three-dimensional crosslinking suitable for load transmission and impact strength improvement. However, their intrinsically low toughness hampers the energy absorption capability, and thermoplastic toughening may improve this aspect. A study from some years ago ${ }^{166}$ focused on improving the impact properties of a hybrid kenaf/glass fiber epoxy bio-composite containing 5 wt\% pCBT (ensuing from insitu ED-ROP of commercial CBT ${ }^{\circledR} 160$ resin added with catalyst). The mechanical properties of the developed hybrid material were almost comparable to those of reference glass fiber compounds, except for impact properties which were improved. The toughened hybrid bio-composite could be used in some automotive structural components, such as car bumpers.

The low viscosity of CBT cycles and their ability to polymerize in situ at relatively low temperatures make them interesting also as additives for rubbery materials. They may indeed reduce the viscosity of uncured, highly filled rubber matrices while the PCBT domains attained by concomitant ED-ROP during vulcanization may work as reinforcement in the cured materials, by forming a highly crystalline dispersed phase. Up to now, few papers have dealt with rubber-based blends exploiting ED-ROP of MCOs to improve properties of the final vulcanizates.

In the first of a series of three works, Karger-Kocsis and co-workers ${ }^{167}$ mixed in a two-roll mixing mill a peroxide-curable hydrogenated acrylonitrile-butadiene rubber (HNBR) with $100 \mathrm{phr}$ (per hundred rubber) of CBT containing a transesterification catalyst. The compounds were cured at $190{ }^{\circ} \mathrm{C}$ for 25 min. Differently from what obtained with neat macrocycles, CBT did not polymerize during rubber curing when incorporated into the HNBR matrix. The authors recorded however a considerable improvement in the stiffness and strength of the hybrids as the CBT cycles worked as an active filler, although their polymerization to pCBT was only partial. Indeed, in the subsequent cooling of HNBR the CBT recrystallized into micron-sized plate-like crystals of high aspect ratio, that greatly improved the mechanical and tribological performance of the HNBR compounds. On the other hand, when the samples (with 50, 100 and 150 phr CBT) were cured at $190{ }^{\circ} \mathrm{C}$ for 25 min and then annealed at $250{ }^{\circ} \mathrm{C}$ for $3 \mathrm{~h}$ under vacuum the conversion of CBT to $\mathrm{PCBT}$ increased up to $70-90 \% .{ }^{168} \mathrm{According}$ to DMTA and AFM, annealing resulted in the formation of a semi-interpenetrating network structure constituted by HNBR and formed pCBT that induces significant improvements on mechanical and tribological properties such as rolling and sliding wear. ${ }^{168,169}$

Similar results were obtained in an analogous trilogy by Halász and Bárány. ${ }^{170-172}$ They investigated the effects of addition of 20 phr CBT without catalyst in apolar and polar elastomers, such as natural rubber (NR), ethylene-propylene-diene rubber (EPDM), styrene-butadiene rubber (SBR), oil-extended or not, acrylonitrilebutadiene rubber (NBR) at different acrylonitrile content or carboxylated (XNBR). CBT macrocycles, acting as a lubricant above their melting temperature, effectively decreased the viscosities of uncured compounds, with consequent improvement of their processability. Due to CBT presence, curing time was adjusted: slightly delayed for NR-, NBR-, XNBR- and EPDM-based compounds, rather anticipated for those SBR-based. All vulcanized rubbers, unable to crystallize under stretching, showed increased tensile and tear strength and surprisingly also enhanced elongation at break. This reinforcing effect exerted by crystallization of CBT partially polymerized to $\mathrm{PCBT}$ is more marked by increasing rubber polarity and arises from stronger CBT-rubber interaction and a finer dispersion of $\mathrm{CBT} / \mathrm{pCBT}$ highly crystalline domains with a mean dimension of few microns. ${ }^{170,172}$ At lower temperatures (below the melting temperature of the oligomers) in apolar rubbers, such as SBR, CBT forms a coarse structure with easily crackable bulky agglomerates sized up to few hundred microns. 
In polar rubbers, such as NBR, the morphology does not change as a function of the mixing temperature, so the final morphology seems to form during the curing process. ${ }^{171}$

ED-ROP reaction of CBT was recently explored by Ferrari and Greco to prepare smart PBT-based materials characterized by self-healing capability. ${ }^{173,174}$ This approach requires the polymer matrix be composed by a mixture of active catalyst, CBT, and PBT. After damaging, a crack is formed on the surface or in the bulk of the material. Heating the material at about $150{ }^{\circ} \mathrm{C}$ allows the melting of the macrocycles, which diffuse inside the crack and fill it thanks to their very low viscosity. They can be then easily converted into pCBT chains, thus promoting a join in-between the broken surfaces and fixing the crack, by increasing the temperature just enough for allowing ED-ROP reaction but staying well below the melting (ca. $225^{\circ} \mathrm{C}$ ) of bulk pCBT, whose presence guarantees shape retention. The authors added an epoxy resin to improve the material toughness and investigated two methods to attain such a partially polymerized system: i) by using two catalysts with different activation temperatures or ii) by intercalating a fast catalyst in-between MMT layers to slow the catalyst activation. Rheological investigations confirmed in both cases the achievement of a two-step reaction: the former activated at lower temperature by the faster catalyst and the latter initiated at higher temperature by the slower catalyst or by the intercalated one. A CBT/pCBT mixture was obtained after the first reaction step, whereas healing and restoring of material properties were obtained during the second step.

\subsection{Materials recycling}

The combination of ED-ROP and CDP processes, based on RCE (see Scheme 1), can potentially represent a suitable method, named as "ring-chain recycling" (RCR), for chemically recycle certain condensation polymers. ${ }^{56}$ The waste polymers can be converted by CDP to MCOs, and these can be readily converted back to highmolecular-weight polymers by ED-ROP in times from minutes to hours. Moreover, the MCOs can be used neat to generate new "virgin" polymers (or copolymers by using mixtures of MCOs of different nature) or even added into a standard condensation polymerization. As before discussed, many applications of MCOs are conceivable also in the field of multicomponent materials, which normally pose recyclability issues.

Polymers potentially recyclable in this way include polyesters, polycarbonates, certain polyamides, and various high-performance aromatic polymers which undergo both CDP in high yield and efficient ED-ROP of the resulting MCOs. ${ }^{56,175}$

The major obstacle to RCR process is improving CDP reaction, since ED-ROP reaction generally works well, is green (no small molecules released and in most cases no solvent required) and could easily be scaled up.

CDP can be carried out in two ways, both of which need a catalyst (generally a traditional transesterification metal-based catalyst). ${ }^{176}$ The first to be used since the 1930s, is thermal CDP generally performed under vacuum without solvent, and useful for polyesters and polycarbonates based on relatively volatile aliphatic monomers and oligomers. ${ }^{12,25,177}$ The obtained MCOs (typically low-molecular weight cycles or cyclic dimers) are distilled away from the reaction mixture over time. The second is CDP in the presence of solvents, mostly conducted at high dilution ( $<3 \% \mathrm{wt} / \mathrm{vol})$ and at lower temperatures than thermal CDP $\left(<200^{\circ} \mathrm{C}\right)$. Although this type of CDP is carried out in mild conditions and leads to high yields, the high dilution is the major barrier to its scaling up for industrial recycling of polymers. Several methods have been suggested by Hodge ${ }^{56}$ to reduce the need for large volumes of solvents and/or long reaction times. For instance, CDP reactions could be carried out continuously by separating the MCOs being formed from the reaction mixtures by means of, e.g., size-selective membranes compatible with organic solvents and elevated temperatures.

Another possibility, as it was discussed above, is starting CDP with a significantly more concentrated solution of the polymer than usual, to obtain polymer/MCOs mixtures containing about 20-30\% of $\mathrm{MCOs}^{6,49}$ which are characterized by a reduced melt viscosity with respect to the polymer alone and can readily restore the high- 
molecular-weight polymer simply by raising the temperature to trigger in-situ ED-ROP of the MCOs present in the mixtures.

CDP could be also performed in a flow system by using insoluble catalysts that can be packed into columns. ${ }^{178,179}$ On the other hand, to reduce the CDP long reaction times, which at present may extend into days, solvents that allow higher reaction temperatures and/or better polymer solubility such as ionic liquids ${ }^{180}$ would be helpful, as well as more efficient catalytic systems. ${ }^{56}$ Polymer-supported catalysts, or clay-supported or silica-supported catalysts, may simplify the removal of the catalyst from the MCOs.

Following this approach, cyclization/depolymerization reactions catalyzed by supported enzymes, that is enzymatic cyclization/depolymerization (EC/ED), have been investigated as well23,24,27,50,56,61,181 to obtain MCOs from monomers or condensation polymers, generally dissolved in organic solvents. Among non-toxic and ecofriendly enzyme catalysts, the commercially available Candida antarctica lipase B (CALB) is the most widely used. ${ }^{24,61,181}$ As for classical RCE, high yields in MCOs are obtained under high dilution conditions; on the contrary, concentrated solutions shift the equilibrium to high-molecular-weight polymers (Figure 3). For instance, Hodge et al. ${ }^{23,61,181}$ explored the effectiveness of polymer-supported CALB in ED-ROP of large lithocholic acid-based macrocycles and of macrocyclic lactones containing bile acid residues obtaining high yields of polymers and copolymers.

As detailed in the recent review of Martinez de llarduya and Munoz Guerra, ${ }^{27}$ a great deal of work on EC/ED has been carried out by their research group and by Matsumura and coworkers ${ }^{182}$ conducted a systematic study on sustainable enzymatic-catalyzed chemical recycling of several aliphatic polyesters, such as PLLA, PBA, PBS, $\mathrm{PCL}, \mathrm{PHB}$, poly(trimethylene carbonate) (PTMC), polythiocaprolactone ( $\mathrm{PTCL})$. The re-polymerization step of MCOs, obtained either by direct synthesis or CDP, was also investigated for the preparation of PBA, PBS, PTMC and PTCL yielding linear polymers with quite high molecular weights. For instance, enzymatic-catalyzed sustainable chemical recycling of polythiocaprolactone (PTCL) was investigated by Shimokawa et al. ${ }^{183}$ who synthesized PTCL by CALB-catalyzed ED-ROP of cyclic 6-mercaptohexanoic acid (CMHA) oligomer obtained by direct synthesis starting from both 6-mercaptohexanoic acid $(6 \mathrm{MH})$ or by CDP of PCTL. Both reactions for CMHA preparation were lipase catalyzed as well. PTCL with $M_{\mathrm{w}}$ as the initial PTCL (ca. $30000 \mathrm{~g} / \mathrm{mol}$ ) and P(TCL-Co-CL) copolymers with different TCL amounts were obtained.

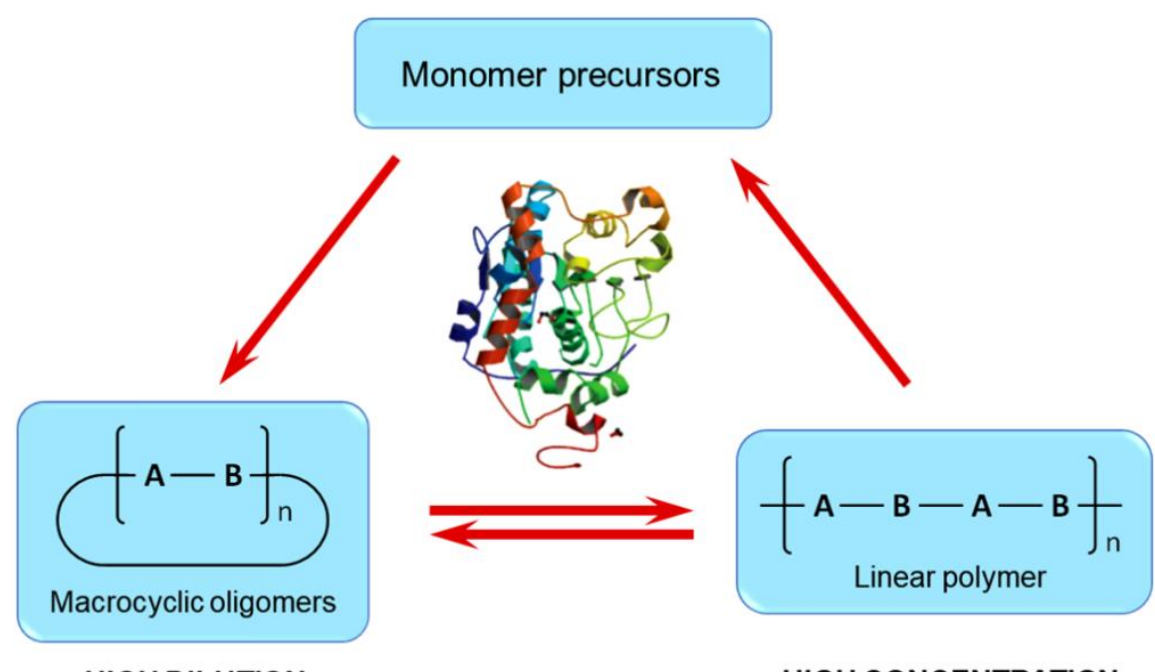

HIGH DILUTION

HIGH CONCENTRATION

Figure 3. Enzyme-catalyzed recycling of polycondensates. 


\section{Conclusions}

In the last three decades, entropically-driven ring-opening polymerization (ED-ROP) of strainless macrocyclic oligomers (MCOs) has become of increasingly interest for the synthesis of condensation polymers, such as polyesters, polycarbonates, certain polyamides, and various high-performance aromatic polymers.

Typical green features of ED-ROP appear perfectly suited to prepare in good yields, at relatively low temperatures and in short times, copolymers of technological interest with controlled composition and microstructure and hence tailored properties, that can respond to a variety of applicative fields (beverages and food packaging, biomedicals, high-performance technical materials) while complying with environmental and sustainability issues posed by social concerns and circular economy.

ED-ROP of MCOs can be advantageously exploited in the manufacturing of multicomponent polymer-based materials, such as blends, composites and nanocomposites to enhance phase adhesion and improve ultimate properties.

ED-ROP is also a useful tool in all those processes where the low melt viscosity of the macrocyclic oligomers and their subsequent facile ring-opening by simply raising the temperature can help the material processing and/or lead to improvement of its final properties.

In a framework of circular economy, ED-ROP nicely combined with the reverse CDP process (or their EC/ED enzymatic counterparts) represent a possible, convenient route to the chemical recycling of condensation polymers, virtually with $100 \%$ atom economy.

\section{Acknowledgements}

This study origins from various Short Term Mobility (STM) Programmes financed over the years by the National Research Council (CNR) of Italy.

\section{References}

1. Jacobson, H.; Stockmeyer, W. H. Intramolecular Reaction in Polycondensations. 1. The Theory of Linear Systems. J. Chem. Phys. 1950, 18, 1600-1606.

https://doi.org/10.1063/1.1747547

2. Jacobson, H.; Stockmeyer, W. H. Intramolecular Reaction in Polycondensations. 2. Ring-Chain Equilibrium in Polydecamethylene Adipate. J. Chem. Phys. 1950, 18, 1607-1612.

https://doi.org/10.1063/1.1747548

3. Semlyen, J. A. In Mechanisms of Polyreactions-Polymer Characterization. Advances in Polymer Science; Springer: Berlin, Heidelberg, 1976; Vol. 21, pp 41-75.

https://doi.org/10.1021/ma00111a007

4. Chen, Z. R.; Claverie, R. H.; Grubbs, R. H.; Kornfield, J. A. Modeling Ring-Chain Equilibria in Ring-Opening Polymerization of Cycloolefins. Macromolecules 1995, 28, 2147-2154.

5. Hodge, P.; Colquhoun, H. M. Recent work on entropically-driven ring-opening polymerizations: some potential applications. Polym. Adv. Technol. 2005, 16, 84-94.

https://doi.org/10.1002/pat.555 
6. Ben-Haida, A.; Colquhoun, H. M.; Hodge, P.; Stanford, J. L. A novel approach to processing highperformance polymers that exploits entropically driven ring-opening polymerization. Macromol. Rapid Commun. 2006, 26, 1377-1382.

https://doi.org/10.1002/marc.200500364

7. Pang, K.; Kotek, R.; Tonelli, A. Review of conventional and novel polymerization processes for polyesters. Prog. Polym. Sci. 2006, 31, 1009-1037.

https://doi.org/10.1016/i.progpolymsci.2006.08.008

8. Brunelle, D. J. Cyclic Polymers (Second Edition), Semlyen, J. A. Ed.; Springer: The Netherlands, 2002; pp 185-228.

9. Kricheldorf, H. R.; Weidner, S. M.; Scheliga, F. Synthesis of cyclic polymers and flaws of the JacobsonStockmayer theory. Polym. Chem. 2020, 11, 2595-2604.

https://doi.org/10.1039/DOPY00226G

10. Hall, A. J.; Hodge, P. Recent research on the synthesis and applications of cyclic oligomers. Reactive Funct. Polym. 1999, 41, 133-139.

https://doi.org/10.1016/S1381-5148(99)00036-X

11. Brunelle, D. J. Cyclic oligomer chemistry. J. Polym. Sci., Part A: Polym. Chem. 2008, 46, 1151-1164. https://doi.org/10.1002/pola.22526

12. Spanagel, E. W.; Carothers, W. H. Macrocyclic esters. J. Am. Chem. Soc. 1935, 57, 929-934. https://doi.org/10.1021/ja01308a046

13. Spanagel, E. W.; Carothers, W. H. Preparation of Macrocyclic Lactones by Depolymerization. J. Am. Chem. Soc. 1936, 58, 654-656.

https://doi.org/10.1021/ja01295a038

14. Ben-Haida, A.; Conzatti, L.; Hodge, P.; Manzini, B.; Stagnaro, P. An Introduction to Entropically-driven Ringopening Polymerizations. Macromol. Symp. 2010, 297, 6-17.

https://doi.org/10.1002/masy.200900109

15. Wang, Y.-F.; Paventi, M.; Hay, A. S. Novel macrocyclic aryl ether oligomers containing a diphenylacetylene moiety: synthesis, characterization and ring-opening polymerization. Polymer 1997, 38, 469-482.

https://doi.org/10.1016/S0032-3861(96)00514-9

16. Brunelle, D. J.; Bradt, J. E.; Serth-Guzzo, J.; Takekoshi, T.; Evans, T. L.; Pearce, E. J.; Wilson, P. R. Semicrystalline Polymers via Ring-Opening Polymerization: Preparation and Polymerization of Alkylene Phthalate Cyclic Oligomers. Macromolecules 1998, 31, 4782-4790.

https://doi.org/10.1021/ma971491j

17. Morales-Huerta, J. C.; Martínez de Ilarduya, A.; Muñoz-Guerra, S. Ring opening polymerization of macrocyclic oligo esters derived from renewable sources. Polymer 2016, 87, 148-158.

https://doi.org/10.1016/i.polymer.2016.02.003

18. Brunelle, D. J.; Shannon, T. G. Preparation and polymerization of bisphenol-A cyclic oligomeric carbonates. Macromolecules 1991, 24, 3035-3044.

https://doi.org/10.1021/ma00011a002

19. Rothe, M.; Zieger, M. Polymer-supported synthesis of series of macrocyclic oligoesters. Tetrahedron Lett. 1994, 35, 9011-9012.

https://doi.org/10.1016/0040-4039(94)88413-7

20. Manzini, B.; Hodge, P. Polymer-supported syntheses of oxo-crown ethers and derivatives containing alphaamino-acid residues. React. Funct. Polym. 2008, 68, 1297-1306.

https://doi.org/10.1016/i.reactfunctpolym.2008.06.003 
21. Hodge, P. Cyclodepolymerization as a method for the synthesis of macrocyclic oligomers. React. Funct. Polym., 2014, 80, 21-32.

https://doi.org/10.1016/i.reactfunctpolym.2013.12.008

22. Fleckenstein, P.; Rosenboom, J.-G.; Storti, G.; Morbidelli, M. Synthesis of Cyclic (Ethylene Furanoate) Oligomers via Cyclodepolymerization. Macromol. React. Eng. 2018, 12, 1800018 (14 pages). https://doi.org/10.1002/mren.201800018

23. Manzini, B.; Hodge, P.; Ben-Haida, A. Entropically-driven ring-opening polymerization of macrocyclic esters with up to 84-membered rings catalysed by polymer-supported Candida antarctica lipase B. Polym. Chem. 2010, 1, 339-346.

https://doi.org/10.1039/B9PY00350A

24. Kundys, A.; Bialecka-Floriańczyk, E.; Fabiszewska, A.; Malajowicz, J. Candida antarctica Lipase B as Catalyst for Cyclic Esters Synthesis, Their Polymerization and Degradation of Aliphatic Polyesters. J. Polym. Environ. 2018, 26, 396-407.

https://doi.org/10.1007/s10924-017-0945-1

25. Hodge, P. Entropically driven ring-opening polymerization of organic macrocycles. Chem. Rev. 2014, 114, 2278-2312 and references therein.

https://doi.org/10.1021/cr400222p

26. Abt, T.; Sanchez-Soto, M. A Review of the Recent Advances in Cyclic Butylene Terephthalate Technology and its Composites. Critical Rev. Solid State Mater. Sci. 2017, 42, 173-217 and references therein. https://doi.org/10.1080/10408436.2016.1160820

27. Martínez de llarduya, A.; Muñoz-Guerra, S. Ring opening polymerization of macrocyclic oligo esters derived from renewable sources. Polym. Chem. 2020, 11, 4850-4860.

https://doi.org/10.1039/DOPY00258E

28. Ben-Haida, A.; Hodge, P.; Colquhoun, H. M. Ring-Chain Interconversion in High-Performance Polymer Systems. 3. Cyclodepolymerization of Poly(m-phenylene isophthalamide) (Nomex) and Entropically Driven Ring-Opening Polymerization of the Macrocyclic Oligomers so Produced. Macromolecules 2005, 38, 722729.

https://doi.org/10.1021/ma0401370

29. Tastard, C. Y.; Hodge, P; Ben-Haida, A; Dobinson, M. Entropically driven ring-opening metathesis polymerization (ED-ROMP) of macrocyclic olefin-containing oligoamides. React. Funct. Polym. 2006, 66, 93-107.

https://doi.org/10.1016/i.reactfunctpolym.2005.07.010

30. Ben-Haida, A.; Colquhoun, H. M.; Hodge, P.; Williams, D. J. Synthesis of a catechol-based poly(ether ether ketone) ("O-PEEK") by classical step-growth polymerization and by entropically-driven ring-opening polymerization of macrocyclic oligomers. Macromolecules 2006, 39, 6467-6472.

https://doi.org/10.1021/ma060885k

31. Kamau, S. D.; Hodge, P.; Williams, R. T.; Stagnaro, P.; Conzatti, L. High Throughput Synthesis of Polyesters Using Entropically-Driven Ring-Opening Polymerizations. J. Comb. Chem. 2008, 10, 644-654. https://doi.org/10.1021/cc800073k

32. Conzatti, L.; Alessi, M.; Stagnaro, P. Hodge, P. Syntheses of Random PET-co-PTTs and Some Related Copolyesters by Entropically-Driven Ring-Opening Polymerizations and by Melt Blending: Thermal Properties and Crystallinity. J. Polym. Sci. Part A: Polym. Sci. 2011, 49, 995-1005.

https://doi.org/10.1002/pola.24513 
33. Alexandre, M.; Dubois, P. Polymer-Layered Silicate Nanocomposites: Preparation, Properties and Uses of a New Class of Materials. Mater. Sci. Eng. 2000, 28, 1-63.

https://doi.org/10.1016/S0927-796X(00)00012-7

34. Jordan, J.; Jacob, K. I.; Tannenbaum, R.; Sharaf, M. A.; Jasiuk, I. Experimental trends in polymer nanocomposites-a review. Mater. Sci. Eng. A 2005, 393, 1-11.

https://doi.org/10.1016/i.msea.2004.09.044

35. Chanda, M.; Roy, S. K. Industrial Polymers, Specialty Polymers, and Their Applications; CRC Press: USA, 2008.

https://doi.org/10.1201/9781420080599

36. Qiao, J.; Guo, M.; Wang, L.; Liu, D.; Zhang, X.; Yu, L.; Song, W.; Liu, Y. Recent advances in polyolefin technology. Polym. Chem. 2011, 2, 1611-1623.

https://doi.org/10.1039/c0py00352b

37. Gahleitner, M.; Resconi, L.; Doshev, P. Heterogeneous Ziegler-Natta, metallocene, and post-metallocene catalysis: Successes and challenges in industrial application. MRS Bulletin 2013, 38, 229-233.

https://doi.org/10.1557/mrs.2013.47

38. Martínez de Ilarduya, A.; Muñoz-Guerra S. Chemical Structure and Microstructure of Poly(alkylene terephthalate)s, their Copolyesters, and their Blends as Studied by NMR. Macromol. Chem. Phys. 2014, 215, 2138-2160.

https://doi.org/10.1002/macp.201400239

39. Paul D. R.; Bucknall C. B. Polymer Blends: Formulations and Performance; Wiley: New York, 2000; Vol 1-2.

40. Akkapeddi M. K. In Polymer Blends Handbook; Utracki, L.; Wilkie, C. Eds.; Springer: Dordrecht, 2014, pp 1733-1883.

https://doi.org/10.1007/978-94-007-6064-6 22

41. Markovic, G.; Visakh, P. M. In Recent Developments in Polymer Macro, Micro and Nano Blends; Visakh, P. M.; Markovic G.; Pasquini, D. Eds.; Woodhead Publishing, 2017, pp 1-15.

https://doi.org/10.1016/B978-0-08-100408-1.00001-7

42. Hull, D.; Clyne, T. W.; An introduction to composite materials (Second Edition); Cambridge University Press, 1996.

https://doi.org/10.1017/CB09781139170130

43. Hsissoua, R.; Seghiria, R.; Zakaria Benzekria, Z.; Hilalib, M. Rafika, M.; Elharfia, A. Polymer composite materials: A comprehensive review. Composit. Struct. 2021, 262, 113640 (15 pages).

https://doi.org/10.1016/i.compstruct.2021.113640

44. Faruk, O.; Bledzki, A. K.; Fink, H. P.; Sain, M. Biocomposites reinforced with natural fibers: 2000-2010, Prog. Polym. Sci. 2012, 37, 1552-1596.

https://doi.org/10.1016/i.progpolymsci.2012.04.003

45. Pickering, K. L.; Aruan Efendy, M. G.; Le, T. M. A review of recent developments in natural fiber composites and their mechanical performance, Compos. Part A: Appl. Sci. Manufact. 2016, 83, 98-112.

https://doi.org/10.1016/i.compositesa.2015.08.038

46. Brunengo, E.; Conzatti, L.; Utzeri, R.; Vicini, S.; Scatto, M.; Verga Falzacappa, E.; Castellano, M.; Stagnaro, $\mathrm{P}$. Chemical modification of hemp fibers by plasma treatment for eco-composites based on biodegradable polyester. J. Mater. Sci. 2019, 54, 14367-14377.

https://doi.org/10.1007/s10853-019-03932-8

47. Sinha Ray, S.; Okamoto, M. Polymer/Layered Silicate Nanocomposites: A Review from Preparation to Processing. Prog. Polym. Sci. 2003, 28, 1539-1641. 
https://doi.org/10.1016/i.progpolymsci.2003.08.002

48. Fu, S.; Sun, Z.; Huang, P.; Li, Y. Q.; Hu, N. Some basic aspects of polymer nanocomposites: A critical review. Nano Mater. Sci. 2019, 1, 2-30.

https://doi.org/10.1016/i.nanoms.2019.02.006

49. Alessi, M.; Conzatti, L.; Hodge, P.; Taglialatela Scafati, S.; Stagnaro, P. A Possible Means to Assist the Processing of PET, PTT and PBT. Macromol. Mater. Eng. 2010, 295, 374-375.

https://doi.org/10.1002/mame.200900307

50. Strandman, S.; Gautrot, J. E.; Zhu, X. X. Recent advances in entropy-driven ring-opening polymerization. Polym. Chem. 2011, 2, 791-799.

https://doi.org/10.1039/COPY00328J

51. Xue, Z.; Mayer, M. F. Entropy-driven ring-opening olefin metathesis polymerizations of macrocycles. Soft Matter 2009, 5, 4600-4611. https://doi.org/10.1039/b913696g

52. Pearce, A. K.; Foster, J. C.; O’Reilly, R. K. Recent Developments in Entropy-Driven Ring-Opening Metathesis Polymerization: Mechanistic Considerations, Unique Functionality, and Sequence Control. J. Polym. Sci., Part A: Polym. Chem. 2019, 57, 1621-1634.

https://doi.org/10.1002/pola.29428

53. Mdivanova, I. R.; Mamkhegov, R. M.; Khashirova, S. Yu.; Ligidov, M. Kh.; Pakhomov, S. I.; Mikitaev, A. K. Cyclic Oligoesters as Potential Materials for Polymer Nanocomposite Production. Russian J. Gen. Chem. 2017, 87, 2195-2203.

https://doi.org/10.1134/S1070363217090468

54. Qin, Y.; Summerscales, J.; Graham-Jones, J.; Meng, M.; Pemberton, R. Monomer Selection for In Situ Polymerization Infusion Manufacture of Natural-Fiber Reinforced Thermoplastic-Matrix Marine Composites. Polymers 2020, 12, 2928 (25 pages).

https://doi.org/10.3390/polym12122928

55. Chen, H.; Yu, W.; Zhou, C. Entropically-driven ring opening polymerization of cyclic butylene terephthalate: Rheology and kinetics. Polym. Eng. Sci. 2012, 52, 91-101.

https://doi.org/10.1002/pen.22050

56. Hodge, P. Recycling of condensation polymers via ring-chain equilibria. Polym. Adv. Technol. 2015, 26 797803.

https://doi.org/10.1002/pat.3469

57. Köpnick, H.; Schmidt, M.; Brügging, W.; Rüter, J.; Kaminsky W. In Ullmann's Encyclopedia of Industrial Chemistry, Wiley-VCH, 2000.

58. Giammanco, G.; Martínez de Ilarduya, A.; Alla, A.; Muñoz-Guerra S. Hydrolyzable Aromatic Copolyesters of p-Dioxanone. Biomacromolecules 2010, 11, 2512-2520.

https://doi.org/10.1021/bm1007025

59. Lee, C. W.; Masutani, K.; Kimura Y. Ring-opening polymerization of a macrocyclic lactone monomer isolated from oligomeric byproducts of poly(butylene succinate) (PBS): An efficient route to highmolecular-weight PBS and block copolymers of PBS. Polymer 2014, 55, 5673-5679.

https://doi.org/10.1016/i.polymer.2014.08.028

60. Morales-Huerta, J. C; Martínez de Ilarduya, A.; Muñoz-Guerra S. Modulating the Tg of Poly(alkylene succinate)s by Inserting Bio-Based Aromatic Units via Ring-Opening Copolymerization. Polymers 2017, 9, 701 (17 pages).

https://doi.org/10.3390/polym9120701 
61. Hodge, P.; Chakiri, A. Entropically-driven ring-opening metathesis polymerization (ED-ROMP) of macrocyclic olefins prepared from deoxycholic acid to give functionalized polymers. Polym. Chem. 2015, 6, 7274-7279. https://doi.org/10.1039/C5PY00272Ahttps://doi.org/10.1016/i.polymer.2019.121591

62. Xu, S.; Wu, F.; Li, Z.; Zhu, X.; Li, X.; Wang, L.; Li, Y.; Tu, Y. A green cascade polymerization method for the facile synthesis of sustainable poly(butylene-co-decylene terephthalate) copolymers. Polymer 2019, 178, 121591 (7 pages).

https://doi.org/10.1016/i.polymer.2019.121591

63. Song, Q.-W. He, L.-N. In Encyclopedia of Sustainability Science and Technology; Meyers, R. A. Ed., Springer Nature 2018.

https://doi.org/10.1007/978-1-4939-2493-6 1001-1

64. Naddeo, M.; D’Auria, I.; Viscusi, G.; Gorrasi, G.; Pellecchia, C.; Pappalardo, D. Tuning the Thermal Properties of Poly(ethylene)-Like Poly(esters) by Copolymerization of $\varepsilon$-Caprolactone with Macrolactones, in the Presence of a Pyridylamidozinc(II) Complex. J. Polym. Sci. 2020, 58, 528-539.

https://doi.org/10.1002/pol.20190085

65. Amador, A. G.; Watts, A.; Neitzel, A. E.; Hillmyer, M. A. Entropically Driven Macrolide Polymerizations for the Synthesis of Aliphatic Polyester Copolymers Using Titanium Isopropoxide. Macromolecules 2019, 52, 2371-2383.

https://doi.org/10.1021/acs.macromol.9b00065

66. Zeng, F.-R.; Liang, Y.; Li, Z.-L. Precision Aliphatic Polyesters via Segmer Assembly Polymerization. Molecules 2018, 23, 452 (15 pages). https://doi.org/10.3390/molecules23020452

67. Weiss, R. M.; Short, A. L.; Meyer, T. Y. Sequence-Controlled Copolymers Prepared via Entropy-Driven RingOpening Metathesis Polymerization. ACS Macro Lett. 2015, 4, 1039-1043.

https://doi.org/10.1021/acsmacrolett.5b00528

68. Nowalk, J. A.; Fang, C.; Short, A. L.; Weiss, R. M.; Swisher, J. H.; Liu, P.; Meyer, T. Y. Sequence-Controlled Polymers Through Entropy-Driven Ring-Opening Metathesis Polymerization: Theory, Molecular Weight Control, and Monomer Design. J. Am. Chem. Soc. 2019, 141, 14, 5741-5752.

https://doi.org/10.1021/jacs.8b13120

69. Hodge, P.; Kamau, S. D.; Ben-Haida, A.; Williams, R. T. Cyclo-depolymerizations of polycarbonates in solution: Use of the macrocyclic oligomers obtained in entropically-driven ring-opening polymerizations and copolymerizations to give carbonate-carbonate and carbonate-carboxylate ester copolymers. React Funct. Polym. 2012, 72, 868-877.

https://doi.org/10.1016/j.reactfunctpolym.2012.07.004

70. Woo, B. G.; Choi, K. Y.; Song, K. H.; Lee, S. H. Melt polymerization of bisphenol-A and diphenyl carbonate in a semibatch reactor. J Appl Polym Sci. 2001, 80, 1253-1266.

https://doi.org/10.1002/app.1211

71. Yan, B. K.; Hou, J. Q.; Wei, C.; Xiao, Y.; Lang, M. D.; Huang, F. R. Synthesis of main chain sulfur-containing aliphatic polycarbonates by organocatalytic ring-opening polymerization of macrocyclic carbonates. Polym. Chem. 2019, 10, 5191-5199.

https://doi.org/10.1039/C9PY01205B

72. McGrail, P. T. Polyaromatics. Polym. Int. 1996, 41, 103-121.

https://doi.org/10.1002/(SICI)1097-0126(199610)41:2<103::AID-PI602>3.0.CO;2-1 
73. Yue, X.; Zhu, M.; Zhang, H.; Liu, B.; Wang, Y.; Jiang Z. Fully aromatic poly(ether ketone)s bearing macrocycle pendants: Synthesis and crosslinking. J. Polym. Sci. Part A: Polym. Chem. 2008, 46, 7002-7010. https://doi.org/10.1002/pola.22986

74. Aricò, F.; Colquhoun, H. M. Catechol-based macrocyclic aromatic ether-sulfones: Synthesis, characterization and ring-opening polymerization. Arkivoc 2021, published online.

https://doi.org/10.24820/ark.5550190.p011.424

75. Behrendt, F. N.; Schlaad, H. Entropy-Driven Ring-Opening Disulfide Metathesis Polymerization for the Synthesis of Functional Poly(disulfide)s. Macromol. Rapid Commun. 2018, 6, 1700735 (4 pages).

https://doi.org/10.1002/marc.201700735

76. Tripathy, A. R.; Chen, W.; Kukureka, S. N. MacKnight, W. J. Novel poly(butylene terephthalate)/poly(vinyl butyral) blends prepared by in situ polymerization of cyclic poly(butylene terephthalate) oligomers. Polymer 2003, 44, 1835-1842.

https://doi.org/10.1016/S0032-3861(03)00029-6

77. Alam, T. M.; Otaigbe, J. U.; Rhoades, D.; Holland, G. P.; Cherry, B. R.; Kotula, P. G. Nanostructured polymer blends: Synthesis and structure. Polymer 2005, 46, 12468-12479.

https://doi.org/10.1016/i.polymer.2005.10.079

78. Bahloul, W.; Bounor-Legare, V.; Fenouillot, F.; Cassagnau, P. EVA/PBT nanostructured blends synthesized by in situ polymerization of cyclic CBT (cyclic butylene terephthalate) in molten EVA, Polymer 2009, 50, 2527-2534.

https://doi.org/10.1016/j.polymer.2009.03.055

79. Abt, T.; Morales de llarduya, A.; Bou, J. J.; Sanchez-Soto, M. Isocyanate toughened pCBT: Reactive blending and tensile properties, eXPRESS Polym. Lett. 2013, 7, 172-185.

https://doi.org/10.3144/expresspolymlett.2013.16

80. van Rijswijk, K.; Bersee, H. E. N. Reactive processing of textile fiber-reinforced thermoplastic composites An overview. Compos. Part A Appl. Sci. Manufact. 2007, 38, 666-681 and references therein.

https://doi.org/10.1016/i.compositesa.2006.05.007

81. Parton, H.; Baets, J.; Lipnik, P.; Goderis, B.; Devaux, J.; Verpoest, I. Properties of poly(butylene terephthatlate) polymerized from cyclic oligomers and its composites. Polymer 2005, 46, 9871-9880.

https://doi.org/10.1016/j.polymer.2005.07.082

82. Parton, H.; Verpoest, I. In situ polymerization of thermoplastic composites based on cyclic oligomers. Polym. Compos. 2005, 26, 60-65.

https://doi.org/10.1002/pc.20074

83. Jang, J.; Park, H. C.; Lee, H. S.; Khil, M.-S.; Kim, S. Y. Electrically and Thermally Conductive Carbon Fiber Fabric Reinforced Polymer Composites Based on Nanocarbons and an In-situ Polymerizable Cyclic Oligoester. Sci. Rep. 2018, 8, 7659 (9 pages).

https://doi.org/10.1038/s41598-018-25965-w

84. Yan, C.; Liu, L.; Zhu, Y.; Xu, H.; Liu, D. Properties of polymerized cyclic butylene terephthalate and its composites via ring opening polymerization. J. Therm. Composit. Mater. 2018, 31, 181-201.

https://doi.org/10.1177/0892705717697774

85. Noh, Y. J.; Lee, S.; Kim, S. Y.; Youn, J. R. High-Speed Fabrication of Thermoplastic Carbon Fiber Fabric Composites with a Polymerizable, Low-Viscosity Cyclic Butylene Terephthalate Matrix for Automotive Applications. Macromol. Res. 2014, 22, 528-533.

https://doi.org/10.1007/s13233-014-2066-1 
86. Liang, W.; Duan, Z.; Yue, J.; Wang, Z.; Osei, B. A. Mechanical Performance of Woven Carbon Fabric Reinforced pCBT Composites with Nanosilica Particles. Polym. Comp. 2017, 2528-2535. https://doi.org/10.1002/pc.23843

87. Zhang, L.; Zhou, L.; Zhang, J.; Wang, Z.; Lu, S.; Wang, X. Influence of high temperature on the flexural properties of GF/pCBT laminates and their fusion-bonded joints. Composit. B Eng. 2017, 110, 124-131. https://doi.org/10.1016/i.compositesb.2016.11.020

88. Mäder, E.; Gao, S.-L.; Plonka, R.; Wang, J. Investigation on adhesion, interphases, and failure behaviour of cyclic butylene terephthalate (CBT $\left.{ }^{\circledR}\right)$ /glass fiber composites. Compos. Sci. Technol. 2007, 67, 3140-3150. https://doi.org/10.1016/i.compscitech.2007.04.014

89. Durai Prabhakaran, R. T.; Pillai, S.; Charca, S.; Oshkovr, S.; Knudsen, H.; Andersen, T.; Bech, J.; Thomsen, O.; Lilholt, H. Effect of polymer form and its consolidation on mechanical properties and quality of glass/PBT composites. Appl. Compos. Mater. 2014, 21, 301-324.

https://doi.org/10.1007/s10443-013-9340-9

90. Baets, J.; Dutoit, M.; Devaux, J.; Verpoest, I. Toughening of glass fiber reinforced composites with a cyclic butylene terephthalate matrix by addition of polycaprolactone. Compos. Part A: Appl. Sci. Manufact. 2008, 39, 13-18.

https://doi.org/10.1016/i.compositesa.2007.09.013

91. Yu, T.; Wu, C. M.; Chang, C. Y.; Wang, C. Y.; Rwei, S. P. Effects of crystalline morphologies on the mechanical properties of carbon fiber reinforcing polymerized cyclic butylene terephthalate composites, eXPRESS Polym. Lett. 2012, 6, 318-328.

https://doi.org/10.1002/pen.23765

92. Kim, S. H.; Noh, Y. J.; Ko, Y. W.; Kim, S. Y.; Youn, J. R. Improved tensile strength and thermal stability of thermoplastic carbon fiber fabric composites by heat induced crystallization of in situ polymerizable cyclic butylene terephthalate oligomers. Polym. Eng. Sci. 2014, 54, 2161-2169.

https://doi.org/10.1002/pc.23314

93. Abt, T.; Karger-Kocsis, J.; Sanchez-Soto, M. Toughened carbon fiber fabric-reinforced pCBT composites, Polym. Compos. 2014, 37, 1453-1460.

https://doi.org/10.1002/pc.23314

94. Wu, W.; Klunker, F.; Xie, L.; Jiang, B.; Ziegmann, G. Simultaneous binding and ex situ toughening concept for textile reinforced $\mathrm{PCBT}$ composites: Influence of preforming binders on interlaminar fracture properties. Compos. Part A Appl. Sci. Manufact. 2013, 53, 190-203.

https://doi.org/10.1016/i.compositesa.2013.06.013

95. Lee, H. S.; Kim, S.-Y.; Noh, Y. J.; Kim, S. Y. Design of microwave plasma and enhanced mechanical properties of thermoplastic composites reinforced with microwave plasma-treated carbon fiber fabric. Compos. Part B Eng. 2014, 60, 621-626.

https://doi.org/10.1016/i.compositesb.2013.12.064

96. Salem, A.; Stewart, K.; Gifford, S.; Berenbaum, A. Fabrication of thermoplastic matrix structural composites by resin transfer molding of cyclic bisphenol-A polycarbonate oligomers. SAMPE J. 1991, 27, 17-22.

97. Higgins, B. A.; Brittain, W.J. Polycarbonate carbon nanofiber composites. Eur. Polym. J. 2005, 41, 889-893. https://doi.org/10.1016/i.eurpolymj.2004.11.040

98. Song, L. N.; Du, X. S.; Xiao, M.; Meng, Y. Z. Short carbon fiber reinforced aromatic polydisulfide derived from cyclic (4,4'-oxybis(benzene)disulfide) via ring-opening polymerization. Polym. Adv. Technol. 2005, 16, 323-327.

https://doi.org/10.1002/pat.587 
99. Misasi, J. M.; Dao, B. N.; Dell'Olio, C.; Swan, S. R.; Issadazeh, S.; Wiggins, J. S.; Varley, R. J. Polyaryletherketone (PAEK) thermoplastic composites via in-situ ring opening polymerization. Comp. Sci. Technol. 2021, 108534 (10 pages). https://doi.org/10.1016/i.compscitech.2020.108534

100. Belgacem, M. N.; Gandini, A. Monomers, Polymers and Composites from Renewable Resources; Elsevier: Oxford UK, 2008.

101. Dicker, M. P. M.; Baker, A. B.; Duckworth, P. F.; Baker, A. B.; Francois, G.; Hazzard, M. K.; Weaver, P. M. Green composites: a review of material attributes and complementary applications, Compos. Part A: Compos. Part A: Appl. Sci. Manufact. 2014, 56, 280-289.

https://doi.org/10.1016/i.compositesa.2013.10.014

102. Gurunathan, T.; Mohanty, S.; Nayak, S. K. A review of the recent developments in biocomposites based on natural fibres and their application perspectives, Compos. Part A: Compos. Part A: Appl. Sci. Manufact. 2015, 77, 1-25.

https://doi.org/10.1016/i.compositesa.2015.06.007

103. Fangueiro, R.; Rana, S. Natural Fibers: Advances in Science and Technology Towards Industrial Applications. From Science to Market; Springer, 2016; Vol. 12. https://doi.org/10.1007/978-94-017-7515-1

104. Gassan, J.; Bledzki, A. K. Thermal degradation of flax and jute fibers. J. Appl. Polym. Sci. 2001, 82, 14171422.

https://doi.org/10.1002/app.1979

105. Chaishome, J.; Brown, K.; Brooks, R.; Clifford, M. J. Thermal Degradation of Flax Fibres as Potential Reinforcement in Thermoplastic Composites. Adv. Mater. Res. 2014, 894, 32-36. https://doi.org/10.4028/www.scientific.net/AMR.894.32

106. Balla, V. K.; Kate, K. H.; Satyavolu, J.; Singh, P., Tadimeti J. G. D. Additive manufacturing of natural fiber reinforced polymer composites: Processing and prospects. Compos. Part B: Eng. 2019, 174, 106956 (4 pages).

https://doi.org/10.1016/i.compositesb.2019.106956

107. Romão, C.M.; Pereira, C.M.; Esteves, J.L. A mechanical analysis of in situ polymerized poly(butylene terephthalate) flax fiber reinforced composites produced by RTM. Conference Papers in Materials Science 2013, 2013, 750802 (5 pages).

https://doi.org/10.1155/2013/750802

108. Romão, C.M.; Esteves, J.L.; Pereira, C.M. ECCM 2012 - Composites at Venice, Proceedings of the 15th European Conference on Composite Materials, Venice, Italy, June 24-28, 2012: (8 pages).

109. Conzatti, L.; Brunengo, E.; Utzeri, R; Castellano, M.; Hodge, P.; Stagnaro, P. Macrocyclic oligomers as compatibilizing agent for hemp fibers/biodegradable polyester eco-composites, Polymer 2018, 146, 396406.

https://doi.org/10.1016/i.polymer.2018.05.053

110. Deshmukh, G. S.; Peshwe, D. R.; Pathak, S. U.; Ekhe, J. D. A study on effect of mineral additions on the mechanical, thermal, and structural properties of poly(butylene terephthalate) (PBT) composites. J. Polym. Res. 2011, 18, 1081-1090.

https://doi.org/10.1007/s10965-010-9510-5

111. Song, J.; Zhang, W.; Yang, W.; Xu, J.; Lai, J. Rheological properties, morphology, mechanical properties, electrical resistivity and EMI SE of cyclic butylene terephthalate/graphite/carbon black composites. J. Polym. Res. 2014, 21, 556 (8 pages). 
https://doi.org/10.1007/s10965-014-0556-7

112. Coluccino, L.; Stagnaro, P.; Vassalli, M.; Scaglione S. Bioactive TGF- $\beta 1 /$ HA alginate-based scaffolds for osteochondral tissue repair: design, realization and multilevel characterization. J. Appl. Biomater. Funct. Biomater. 2016, 14, E42-E52.

https://doi.org/10.5301/jabfm.5000249

113. Malikmammadov, E.; Tanir, T. E.; Kiziltay, A.; Hasirci V.; Hasirci N. PCL and PCL-based materials in biomedical applications. J. Biomater. Sci., Polym. Ed. 2018, 29, 863-893. https://doi.org/10.1080/09205063.2017.1394711

114. Gigli, M.; Fabbri, M.; Lotti, N.; Gamberini, R.; Rimini, B.; Munari, A. Poly(butylene succinate)-based polyesters for biomedical applications: A review. Eur. Polym. J. 2016, 75, 431-460.

https://doi.org/10.1016/i.eurpolymj.2016.01.016

115. Suebwongnat, S.; Jianprasert, A.; Siriphannon P.; Monvisade, P. Calcium silicate/poly(ethylene terephthalate) biomaterials via ring-opening polymerization. J. Polym. Res. 2012, 19:9985 (7 pages). https://doi.org/10.1007/s10965-012-9985-3

116. Siriphannon, P.; Monvisade, P. Poly(ethylene terephthalate)/hydroxyapatite biomaterials: Preparation, characterization, and in vitro bioactivity J. Biomed. Mat. Res. A 2008, 464-469. https://doi.org/10.1002/jbm.a.31797

117. Siriphannon, P.; Monvisade, P. In situ ring-opening polymerization of hydroxyapatite/poly(ethylene adipate)-co-(ethylene terephthalate) biomimetic composites Bull. Mat. Sci. 2013, 36, 121-128. https://doi.org/10.1007/s12034-013-0427-6

118. Pei, S. G.; Kar, C. W.; Ahamad, F. I. Nanocomposite Membranes for Liquid and Gas Separations from the Perspective of Nanostructure Dimensions. Membranes 2020, 10, 297 (29 pages). https://doi.org/10.3390/membranes10100297

119. Ngô, C.; Van de Voorde, M. In Nanotechnology in a nutshell: From Simple to Complex Systems; Atlantis Press, 2014, pp. 75-77. https://doi.org/10.2991/978-94-6239-012-6

120. Lee, S.-S.; Young T. M.; Rhee, H.-W.; Kim, J. Exfoliation of layered silicate facilitated by ring-opening reaction of cyclic oligomers in PET-clay nanocomposites. Polymer 2005, 46, 2201-2210. https://doi.org/10.1016/j.polymer.2005.01.006

121. Pavlidou, S.; Papaspyrides, C. D. A review on polymer-layered silicate nanocomposites. Prog. Polym. Sci. 2008, 33, 1119-1198.

https://doi.org/10.1016/j.progpolymsci.2008.07.008

122. Young, R. J.; Kinloch, I. A.; Gong, L.; Novoselov, K. S. The mechanics of graphene nanocomposites: A review. Compos. Sci. Technol. 2012, 72, 1459-1476.

https://doi.org/10.1016/i.compscitech.2012.05.005

123. Jiang, Z.; Siengchin, S.; Zhou, L.-M.; Steeg, M.; Karger-Kocsis, J.; Man, H. C. Poly(butylene terephthalate)/silica nanocomposites prepared from cyclic butylene terephthalate. Composit. Part A: Appl. Sci. Manufact. 2009, 40, 273-278.

https://doi.org/10.1016/i.compositesa.2008.12.003

124. Yang, B.; Zhou, L.; Zhang, J.; Zhang, L. Preparation, Mechanical and Thermal Properties of Poly(butylene terephthalate) and Its Nanocomposites Prepared from Cyclic Butylene Terephthalate Polym. Polym. Composit. 2015, 23, 103-108.

https://doi.org/10.1177/096739111502300206 
125. Tripathy, A. R.; Elmoumni, A.; Winter, H. H.; MacKnight, W. J. Effects of Catalyst and Polymerization Temperature on the In-Situ Polymerization of Cyclic Poly(Butylene Terephthalate) Oligomers for Composite Applications. Macromolecules 2005, 38, 709-715. https://doi.org/10.1021/ma0483874

126. Mohd Ishak, Z. A.; Gatos, K. G.; Karger-Kocsis J. On the in situ polymerization of cyclic butylene terephthalate oligomers: DSC and rheological studies. Polym. Eng. Sci. 2006, 46, 743-750. https://doi.org/10.1002/pen.20486

127. Zhu, Y.; Murali, S.; Cai, W.; Li, X.; Suk, J. W.; Potts, J. R.; Ruoff, R. S. Graphene and Graphene Oxide: Synthesis, Properties, and Applications. Adv. Mater. 2010, 22, 3906-3924.

https://doi.org/10.1002/adma.201001068

128. Huang, Z.; Li, L.; Wang, Y.; Zhang, C.; Liu, T. X. Polyaniline/graphene nanocomposites towards highperformance supercapacitors: A review. Compos. Commun. 2018, 8, 83-91.

https://doi.org/10.1016/i.coco.2017.11.005

129. Colonna, S.; Battegazzore, D.; Eleuteri, M.; Arrigo, R.; Fina, A. Properties of Graphene-Related Materials Controlling the Thermal Conductivity of Their Polymer Nanocomposites. Nanomaterials 2020, 10, 2167 (20 pages).

https://doi.org/10.3390/nano10112167

130. Kuilla, T.; Bose, S.; Mishra, A. K.; Khanra, P.; Kim, N. H.; Lee, J. H. Chemical functionalization of graphene and its applications. Prog. Mater. Sci. 2012, 57, 1061-1105.

https://doi.org/10.1016/j.pmatsci.2012.03.002

131. Kuilla, T.; Bhadra, S.; Yao, D.; Kim, N. H.; Bose, S.; Lee, J. H. Recent advances in graphene based polymer composites. Prog. Polym. Sci. 2010, 35, 1350-1375.

https://doi.org/10.1016/i.progpolymsci.2010.07.005

132. Tripathy, A. R.; Burgaz, E.; Kukureka, S. N.; MacKnight, W. J. Poly(butylene terephthalate) nanocomposites prepared by in-situ polymerization. Macromolecules 2003, 36, 8593-8595.

https://doi.org/10.1021/ma021364+

133. Karger-Kocsis, J.; Shang, P. P.; Mohd Ishak, Z. A. Rösch, M. Melting and crystallization of in-situ polymerized cyclic butylene terephthalates with and without organoclay: A modulated DSC study, eXPRESS Polym. Lett. 2007, 1, 60-68.

https://doi.org/10.3144/expresspolymlett.2007.12

134. Berti, C.; Binassi, E.; Colonna, M.; Fiorini, M.; Zuccheri, T.; Karanam, S.; Brunelle, D. J. Improved dispersion of clay platelets in poly(butylene terephthalate) nanocomposite by ring-opening polymerization of cyclic oligomers: Effect of the processing conditions and comparison with nanocomposites obtained by melt intercalation. J. Appl. Polym. Sci. 2009, 114, 3211-3217.

https://doi.org/10.1002/app.30957

135. Wu F. M.; Yang, G. S. Poly(butylene terephthalate)/organoclay nanocomposites prepared by in-situ bulk polymerization with cyclic poly(butylene terephthalate). Mater. Lett. 2009, 63, 1686-1688. https://doi.org/10.1016/i.matlet.2009.05.011

136. Hong, S. C.; Lee, S.-S. Temperature-dependent decyclopolymerization of cyclic oligomers and the implication on destructuring layered nanosheets for nanocomposite reinforcement. Compos. Sci. Technol. 2013, 86, 170-176. https://doi.org/10.1016/i.compscitech.2013.07.018 
137. Conzatti, L.; Utzeri, R.; Hodge, P.; Stagnaro, P. A novel tin-based imidazolium-modified montmorillonite catalyst for the preparation of poly(butylene terephthalate)-based nanocomposites using in situ entropically-driven ring-opening polymerization. RSC Adv. 2015, 5, 6222-6231. https://doi.org/10.1039/C4RA12983K

138. Huang, X.; Lewis, S.; Brittain, W. J.; Vaia, R. A. Synthesis of Polycarbonate-Layered Silicate Nanocomposites via Cyclic Oligomers. Macromolecules 2000, 33, 2000-2004.

https://doi.org/10.1021/ma991709x

139. Lanciano, G.; Greco, A.; Maffezzoli, A.; Mascia, L. Effects of thermal history in the ring opening polymerization of $\mathrm{CBT}$ and its mixtures with montmorillonite on the crystallization of the resulting poly(butylene terephthalate). Thermochim. Acta 2009, 493, 61-67.

https://doi.org/10.1016/i.tca.2009.04.004

140. González-Vidal, N.; Muñoz-Guerra, S.; Martínez de llarduya, A.; Benali, S.; Peeterbroeck, S.; Dubois, P. Poly (hexamethylene terephthalate)-layered silicate nanocomposites, Eur. Polym. J. 2010, 46, 156-164. https://doi.org/10.1016/i.eurpolymj.2009.10.018

141. Wan, C.; Zhao, F.; Bao, X.; Kandasubramanian, B.; Duggan, M. Surface Characteristics of Polyhedral Oligomeric Silsesquioxane Modified Clay and Its Application in Polymerization of Macrocyclic Polyester Oligomer. J. Phys. Chem. B 2008, 112, 11915-11922.

https://doi.org/10.1021/ip805259q

142. Xie, W.; Gao, Z.; Pan, W.-P.; Hunter, D.; Singh, A.; Vaia, R. Thermal Degradation Chemistry of Alkyl Quaternary Ammonium Montmorillonite. Chem. Mater. 2001, 13, 2979-2990.

https://doi.org/10.1021/cm010305s

143. Cavani, F.; Trifirò, F.; Vaccari A. Hydrotalcite-type anionic clays: Preparation, properties and applications. Catal. Today 1991, 11, 173-301. https://doi.org/10.1016/0920-5861(91)80068-K

144. Berti, C.; Fiorini, M.; Sisti, L. Synthesis of poly(butylene terephtahlate) nanocomposites using anionic clays. Eur. Polym. J. 2009, 45, 70-78.

https://doi.org/10.1016/i.eurpolymj.2008.09.039

145. Du, X.; Xiao, M.; Meng, Y.; Hay, A.S. Synthesis of poly(arylene disulfide)-vermiculite nanocomposites via in situ ring-opening polymerization of macrocyclic oligomers. Polym. Int. 2004, 53, 789-793. https://doi.org/10.1002/pi.1451

146. Chen, H.; Huang, C.; Yu, W.; Zhou, C. Effect of thermally reduced graphite oxide (TrGO) on the polymerization kinetics of poly(butylene terephthalate) (pCBT)/TrGO nanocomposites prepared by in situ ring-opening polymerization of cyclic butylene terephthalate. Polymer 2013, 54, 1603-1611. https://doi.org/10.1016/i.polymer.2013.01.036

147. Colonna, S.; Bernal, M. M.; Gavoci, G.; Gomez, J.; Novara, C.; Saracco, G.; Fina, A. Effect of processing conditions on the thermal and electrical conductivity of poly (butylene terephthalate) nanocomposites prepared via ring-opening polymerization. Mat. Des. 2017, 119, 124-132.

https://doi.org/10.1016/i.matdes.2017.01.067

148. Colonna, S.; Monticelli, O.; Gomez, J.; Saracco, G.; Fina A. Morphology and properties evolution upon ringopening polymerization during extrusion of cyclic butylene terephthalate and graphene-related-materials into thermally conductive nanocomposites. Eur. Polym. J. 2017, 89, 57-66. https://doi.org/10.1016/i.eurpolymj.2017.02.011

149. Potts, J. R.; Dreyer, D. R.; Bielawski C. W.; Ruoff R. S. Graphene-based polymer nanocomposites. Polymer 2011, 52, 5-25. 
https://doi.org/10.1016/i.polymer.2010.11.042

150. Du, X.S.; Xiao, M.; Meng, Y.Z.; Hay A.S. Synthesis and properties of poly (4,4'-oxybis (benzene) disulfide)/graphite nanocomposites via in situ ring-opening polymerization of macrocyclic oligomers. Polymer 2004, 45, 6713-6718.

https://doi.org/10.1016/i.polymer.2004.07.026

151. Ma, P.-C.; Siddiqui, N.A.; Marom, G.; Kim, J.-K. Dispersion and functionalization of carbon nanotubes for polymer-based nanocomposites: A review. Composit. Part A Appl. Sci. Manufact. 2010, 41, 1345-1367. https://doi.org/10.1016/i.compositesa.2010.07.003

152. Salvetat, J.P.; Bonard, J.M.; Thomson, N.H.; Kulik, A.J.; Forró, L.; Benoit, W.; Zuppiroli, L. Mechanical properties of carbon nanotubes. Appl. Phys. A 1999, 69, 255-260.

https://doi.org/10.1007/s003390050999

153. Wu, F.; Yang, G. Synthesis and properties of poly (butylene terephthalate)/multiwalled carbon nanotube nanocomposites prepared by in situ polymerization and in situ compatibilization, J. Appl. Polym. Sci. 2010, 118, 2929-2938.

https://doi.org/10.1002/app.32625

154. Wu, F.; Yang, G. Poly(butylene terephthalate)-functionalized MWNTs by in situ ring-opening polymerization of cyclic butylene terephthalate oligomers. Polym. Adv. Technol. 2011, 22, 1466-1470. https://doi.org/10.1002/pat.1762

155. Gonzalez-Vidal, N.; Martinez de Ilarduya, A.; Munoz-Guerra, S.;. Castell, P.; Martinez, M. T. Synthesis and properties of poly(hexamethylene terephthalate)/multiwall carbon nanotubes nanocomposites. Compos. Sci. Technol. 2010, 70, 789-796. https://doi.org/10.1016/i.compscitech.2010.01.014

156. Kuo, S.-W.; Chang, F.-C. POSS related polymer nanocomposites. Prog. Polym. Sci. 2011, 36, 1649-1696. https://doi.org/10.1016/j.progpolymsci.2011.05.002

157. McLauchlin, A.; Bao, X.; Zhao, F. Organoclay polybutylene terephthalate nanocomposites using dual surfactant modified montmorillonite prepared by the masterbatch method. Appl. Clay Sci. 2011, 53, 749753.

https://doi.org/10.1016/i.clay.2011.07.006

158. Wu, F.; Xie, T.; Yang, G. Characterization of PBT/POSS nanocomposites prepared by in situ polymerization of cyclic poly(butylene terephthalate) initiated by functionalized POSS. J. Polym. Sci. Part B: Polym. Phys. 2010, 48, 1853-1859.

https://doi.org/10.1002/polb.22060

159. Manolakis, I.; Colquhoun, H.M. Ring-opening polymerization in molten PEEK: transient reduction of meltviscosity by macrocyclic aromatic thioetherketones. J. Mater. Chem., 2012, 22, 20458-20464. https://doi.org/10.1039/c2jm32496b

160. Sumita, M.; Sakata, K.; Hayakawa, Y.; Asai, S.; Miyasaka, K.; Tanemura, M. Double percolation effect on the electrical conductivity of conductive particles filled polymer blends, Colloid Polym. Sci. 1992, 270, 134139.

https://doi.org/10.1007/BF00652179

161. Abbasi, S.; Derdouri, A.; Carreau, P. J. Carbon nanotube conductive networks through the double percolation concept in polymer systems. Int. Polym. Proc. 2014, 29, 13-27.

https://doi.org/10.3139/217.2778

162. Song, J. B.; Zhong, Y. M.; Lin, S. Y.; Lan, L. S.; Yang, W. B. The Study of Volume Electrical Resistivity and Mechanical Property of Double Continuous Phase PVDF/CBT Composite Containing Carbon Black and 
Graphite. Advanced. Materials Research, Vol. 838-841, Trans Tech Publications, Ltd., Nov. 2013, pp. 107110.

https://doi.org/10.4028/www.scientific.net/amr.838-841.107

163. Szeluga, U.; Kumanek, B.; Trzebicka, B. Synergy in hybrid polymer/nanocarbon composites. A review. Compos. Part A Appl. Sci. Manufact. 2015, 73, 204-231.

https://doi.org/10.1016/i.compositesa.2015.02.021

164. Kim, H. S.; Kim, J. H.; Yang, C.-M.; Kim, S. Y. Synergistic enhancement of thermal conductivity in composites filled with expanded graphite and multi-walled carbon nanotube fillers via melt-compounding based on polymerizable low-viscosity oligomer matrix. J. Alloys Comp. 2017, 690, 274-280.

https://doi.org/10.1016/i.jallcom.2016.08.141

165. Astigarraga, V.; Gondra, K.; Valea, Á.; Pardo Aurrekoetxea, G. Improvement of adhesive bonding of polypropylene and maleic anhydride grafted polypropylene blends to aluminium by means of addition of cyclic butylene terephthalate, J. Adhes. 2018, 1437415 (23 pages).

https://doi.org/10.1080/00218464.2018.1437415

166. Davoodi, M. M.; Sapuan, S. M.; Ahmad, D.; Aidy, A.; Khalina, A.; Jonoobi, M. Effect of polybutylene terephthalate (PBT) on impact property improvement of hybrid kenaf/glass epoxy composite. Mater. Lett. 2012, 67, 5-7.

https://doi.org/10.1016/i.matlet.2011.08.101

167. Karger-Kocsis, J.; Felhõs, D.; Bárány, T.; Czigány T. Hybrids of HNBR and in situ polymerizable cyclic butylene terephthalate (CBT) oligomers: properties and dry sliding behavior. eXPRESS Polym. Lett. 2008, 2, 520-527. https://doi.org/10.3144/expresspolymlett.2008.62

168. Xu, D.; Karger-Kocsis, J.; Apostolov, A. A. Hybrids from HNBR and in situ polymerizable cyclic butylene terephthalate (CBT): Structure and rolling wear properties. Eur. Polym. J. 2009, 45, 1270-1281. https://doi.org/10.1016/i.eurpolymi.2008.11.029

169. Xu, D.; Karger-Kocsis, J. Rolling and sliding wear properties of hybrid systems composed of uncured/cured HNBR and partly polymerized cyclic butylene terephthalate (CBT). Tribol. Int. 2010, 43, 289-298. https://doi.org/10.1016/i.triboint.2009.06.008

170. Halász, I. Z.; Bárány, T. Novel Bifunctional Additive for Rubbers: Cyclic Butylene Terephthalate Oligomer. Period. Polytech. Chem. Eng. 2015, 59, 182-188.

https://doi.org/10.3311/PPme.8321

171. Halász, I. Z.; Bárány, T. Phase Morphology and Mechanical Properties of Cyclic Butylene Terephthalate Oligomer-Containing Rubbers: Effect of Mixing Temperature. Materials 2016, 9, 722 (11 pages). https://doi.org/10.3390/ma9090722

172. Halász, I. Z.; Bárány, T. Effect of Cyclic Butylene Terephthalate Oligomer on the Properties of StyreneButadiene and Acrylonitrile-Butadiene Rubbers. Period. Polytech. Chem. Eng. 2018, 62, 32-42. https://doi.org/10.3311/PPch.10913

173. Ferrari, F.; Greco, A. Thermal analysis of self-healing thermoplastic matrix nanocomposite from cyclic butylene terephthalate. J. Therm. Anal. Calorim. 2018, 134, 567-574.

https://doi.org/10.1007/s10973-018-7135-9

174. Ferrari, F.; Greco, A. An Innovative Approach for Restoring the Mechanical Properties of ThermoplasticMatrix Nanocomposite by the Use of Partially Polymerized Cyclic Butylene Terephthalate. J. Compos. Sci. 2020, 4, 146 (11 pages). https://doi.org/10.3390/jcs4040146 
175. Endo, T.; Kakimoto, K.; Ochiai, B.; Nagai, D. Synthesis and Chemical Recycling of a Polycarbonate Obtained by Anionic Ring-Opening Polymerization of a Bifunctional Cyclic Carbonate Macromolecules 2005, 38, 8177-8182.

https://doi.org/10.1021/ma050791v

176. Kosloski-Oh, S. C.; Wood, Z. A.; Manjarrez, Y.; de los Rios, J. P.; Fieser M. E. Catalytic methods for chemical recycling or upcycling of commercial polymers. Mater. Horiz. 2021, 8, 1084-1129.

ttps://doi.org/10.1039/D0MH01286F

177. Hill, J. W.; Carothers, W. H. Studies of Polymerization and Ring Formation. XX. Many-Membered Cyclic Esters J. Am. Chem. Soc. 1933, 55, 5031-5039.

https://doi.org/10.1021/ja01339a055

178. Kaihara, S.; Osanai, Y.; Nishikawa, K.; Toshima, K.; Doi, Y.; Matsumura, S. Enzymatic transformation of bacterial polyhydroxyalkanoates into repolymerizable oligomers directed towards chemical recycling, Macromol. Biosci. 2005, 5, 644-652.

https://doi.org/10.1002/mabi.200500030

179. Osanai, Y.; Toshima, K.; Matsumura, S. Transformation of biodegradable polyesters into cyclic oligomers under continuous flow using an enzyme-packed column. Macromol. Biosci. 2004, 4, 936-942. https://doi.org/10.1002/mabi.200400046

180. Zhang, S.; Lemaire, V.; Féret, A.; Lefebvre, H.; Tessier, M.; Fradet, A. Synthesis of linear and hyperbranched polyesters in Brønsted acid ionic liquids. Polym. Chem. 2013, 4, 1538-1545.

https://doi.org/10.1039/C2PY20888A

181. Hodge, P.; Chakiri, A. The use of polymer-supported Candida antarctica lipase $B$ to achieve the entropicallydriven ring-opening polymerization of macrocyclic bile acid derivatives via transesterification: selectivity of the reactions and the structures of the polymers produced. RSC Avd. 2015, 5, 93057-93066.

https://doi.org/10.1039/C5RA17954H

182. Yagihara, T.; Matsumura, S. Enzymatic Synthesis and Chemical Recycling of Novel Polyester-Type Thermoplastic Elastomers. Polymers 2012, 4, 1259-1277. https://doi.org/10.3390/polym4021259

183. Shimokawa, K.; Kato, M.; Matsumura, S. Enzymatic Synthesis and Chemical Recycling of Polythiocaprolactone. Macromol. Chem. Phys. 2011, 212, 150-158.

https://doi.org/10.1002/macp.201000488 


\section{Authors' Biographies}

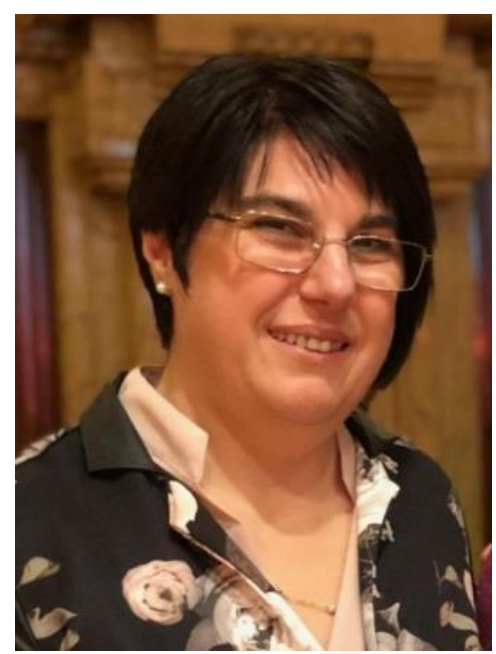

Paola Stagnaro is a Senior Researcher, responsible for SCITEC-CNR section of Genoa, Italy. 1989, Degree in Chemistry, magna cum laude. 1993, PhD in Chemical Sciences. Her research activity has started on novel synthetic routes in the field of aromatic and heterocyclic organic chemistry. The acquired expertise has been then exploited to synthesize novel monomers and study the ensuing polycondensation and polyaddition systems for applications as liquid crystals, membranes, optoelectronics, food packaging. Over the years she has devoted her studies on formulation and development of new multicomponent polymer-based materials (copolymers, blends, composites and nanocomposites), focusing on process-structure-morphology-properties relationship, for applications in food packaging and agro-food, automotive and green tires, energy storage and harvesting, addressing safety, eco-sustainability and circular economy issues. Responsible for numerous competitive research projects and contracts with industries. Author of almost 110 indexed papers, 9 book chapters, and other publications.

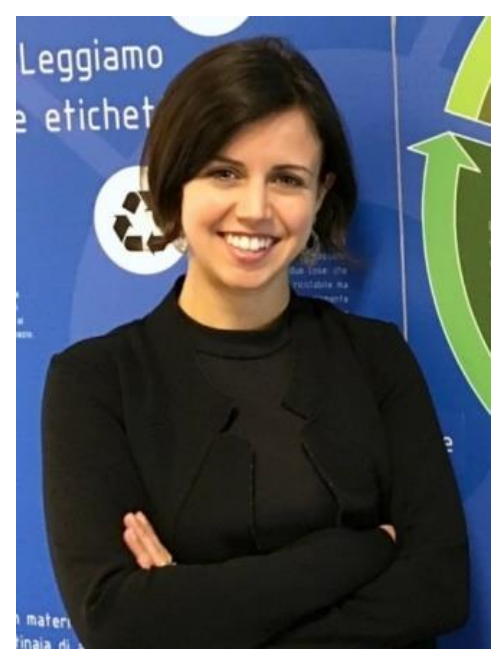

Elisabetta Brunengo is a Research Fellow at SCITEC-CNR section of Genoa, Italy from 2016 to 2021. 2014, Degree in Materials Science, magna cum laude. 2016, Degree in Materials Science and Engineering, magna cum laude. 2021, PhD in Chemical Sciences and Technologies, magna cum laude. Her training and research paths have been strongly based on polymers and polymer-based composites for applications in the field of energy harvesting as well as on bio-polymers and bio-composites for environmental sustainability purposes. She worked on composites preparation and characterization addressing the issue of components compatibilization and 
focusing on filler/fibers functionalization and correlation of process-structure-morphology with the ultimate material properties. During her research activity at Italian National Research Council she worked in the framework of National and International projects. Author of 10 indexed papers.

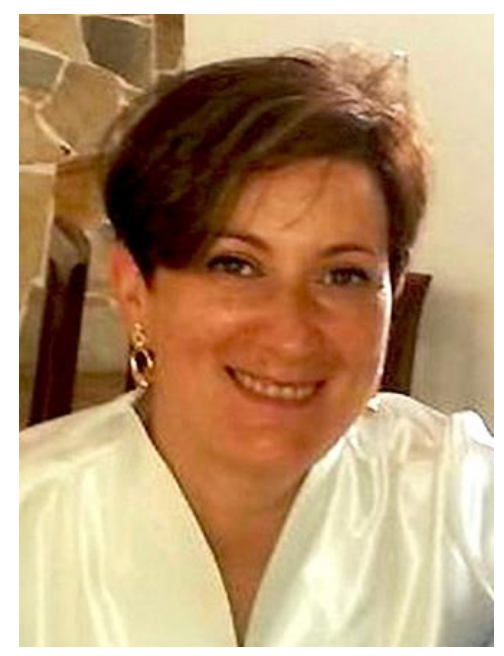

Lucia Conzatti is a Researcher at SCITEC-CNR section of Genoa, Italy. 2000, Degree in Chemistry. 2005, PhD in Chemical Sciences. Her research activity, performed within funded research projects, has started on synthesis and characterization of substituted polyacetylenes and alkyl-aromatic polyesters and then moved to design and study of innovative multiphasic polymer-based materials (blends, composites, and nanocomposites) for application fields, such as food packaging, energy storage, tires, and automotive industry. Relationships among structure, morphology, and properties have been particularly explored. The expertise acquired on thermoplastic- and elastomer-based materials has been then exploited to address eco-sustainability and circular economy issues by dealing with biodegradable polymer-based materials and/or biomass/wastes valorization. Responsible for contracts with industries and involved in scientific dissemination activities. Author of almost 80 indexed papers, 5 book chapters, and other publications. 